\title{
Agricultural productivity, structural change, and economic growth in post-reform China ${ }^{\hbar}$
}

\author{
Kang Hua Cao ${ }^{\text {a }}$, Javier A. Birchenall ${ }^{\mathrm{b}, *}$ \\ a U.S. Department of Transportation, United States \\ ${ }^{\mathrm{b}}$ University of California at Santa Barbara, United States
}

\section{A R T I C L E I N F O}

Article history:

Received 7 July 2011

Received in revised form 13 May 2013

Accepted 7 June 2013

\section{Keywords:}

China

Agricultural productivity

Structural change

Economic growth

\begin{abstract}
A B S T R A C T
We examine the role of agricultural productivity as a determinant of China's post-reform economic growth and sectoral reallocation. Using microeconomic farm-level data, and treating labor as a highly differentiated input, we find that the labor input in agriculture decreased by $5 \%$ annually and agricultural TFP grew by $6.5 \%$. Using a calibrated two-sector general equilibrium model, we find that agricultural TFP growth: (i) accounts for the majority of output and employment reallocation toward non-agriculture; (ii) contributes (at least) as much to aggregate and sectoral economic growth as non-agricultural TFP growth; and (iii) influences economic growth primarily by reallocating workers to the non-agricultural sector, where rapid physical and human capital accumulation are currently taking place.
\end{abstract}

Published by Elsevier B.V.

\section{Introduction}

Market-oriented reforms have brought unprecedented growth to China. China's economic growth has been accompanied by farreaching changes in the structure of output and employment, and by a rapid spatial reallocation of labor toward urban areas. China's growth experience constitutes one of the most striking economic episodes in modern history. Understanding the sources of China's growth is important if not least because China's experience could shed light on the growth potential of other developing countries. This paper studies the role of agricultural productivity in China's economic growth and related structural changes during the reform period. The role of agriculture in China's growth is particularly important. The related theoretical literature and policy debate are both conflicted on the subject of agriculture. Is agricultural growth a necessary condition for overall

\footnotetext{
We would like to thank our two anonymous referees, whose comments greatly improved the paper. We would also like to thank Henning Bohn, Kam Wing Chan, Liming Chen, Igor Livshits, Hui He, Marek Kapicka, Tee Kilenthong, Finn Kydland, Wei Lin, Aashish Mehta, Cheng-Zhong Qin, Peter Rupert, Guillaume Vandenbroucke, Xintong Yang, and the seminar participants from a number of different venues for their comments. All errors are our own.

* Corresponding author at: Department of Economics, 2127 North Hall, University of California, Santa Barbara, CA 93106, United States. Tel.: +1 8058935275.

E-mail address: jabirche@econ.ucsb.edu (J.A. Birchenall).
}

economic growth? Or is agriculture pulled along by the productivity growth taking place in non-agricultural sectors?

Crucial for understanding China's transformation are the total factor productivities of agricultural and non-agricultural sectors. Young (2003) carried out a careful growth accounting exercise for China's non-agricultural sector. So far, however, no similar exercises are available for the agricultural sector. The existing macroeconomic literature approaches Chinese agriculture by examining aggregate data only; see, e.g., Chow (1993), Fan and Zhang (2002), Fan et al. (2003), and Dekle and Vandenbroucke (2010, 2012). Aggregate data, however, fails to provide a proper measure of the growth of the labor input that accounts for differences in the workforce's human capital. Since variations over time in the composition of the labor input are likely to explain China's agricultural growth, in order to measure effective labor units, we need to control for the changing characteristics of agricultural workers.

Constructing a proper measure of the labor input in agriculture is challenging. The fundamental difficulty is that in China, as well as in most developing economies, a large proportion of the income of an agricultural household comes from the combination of factor rewards (land, labor, and capital) rather than from wage income. This implies that there is no explicit observable individual wage, excepting a small and highly selective sample of agricultural workers. Without agricultural wages, it is not possible to quantify the relative productivities of different types of labor, and hence their contribution to the aggregate labor input. In the absence of wage data, it is not possible to measure 
agricultural productivity using the standard approach, such as that used by Young (2003, Section II). ${ }^{1}$

The first contribution of this paper is to estimate the total factor productivity (TFP) growth of China's agricultural sector between 1991 and 2009, accounting for the fact that labor is a highly differentiated input. Using the China Health and Nutrition Survey (CHNS), we obtain detailed measures of income for all household members and for households themselves. The CHNS also reports detailed time-use data. The main methodological novelty of our strategy is the use of the average product of labor to measure the aggregate labor input in agriculture. We find that between 1991 and 2009, China's agricultural labor input decreased at a rate of 4.5-5.5\% annually and that, on average, agricultural TFP grew by $6.5 \%$. This growth rate is more than four times the level Alwyn Young estimated for the non-agricultural sector in China (1.4\%) and twice as large as the estimate of non-agricultural TFP in China based on official data (3.0\%); see Young (2003, Table 24).

China's rate of growth in agricultural TFP is not unprecedented, especially within the context of the rapidly growing economies of Southeast Asia. However, despite the broad scope of reforms and reduced state control over labor mobility, the Chinese economy has remained distorted. Thus, any attempt to measure agricultural productivity in China has to deal with market distortions. To ensure that our measure of the effective labor of the various types of workers is robust, we perform a number of checks. ${ }^{2}$ We examine the influence of state controlled prices on the estimated wage profiles, and we consider rural coastal and rural inland areas separately. State controlled prices, where available, provide a direct measure of the price distortions confronting farmers. Similarly, we employ the estimated differences in the effective labor units across regions as an indirect assessment of the significance of labor mobility restrictions. Our estimates of the labor input and TFP are remarkably stable across specifications.

The second contribution of this paper is to quantify the importance of agricultural and non-agricultural TFP in contributing to China's growth and its structural transformation during the reform period. These questions require an economy-wide representation of the Chinese economy. The economic growth literature describes structural change as occurring primarily in two ways: through non-homothetic preferences and through sectoral differences in the production functions. ${ }^{3}$ In this paper, we rely on a two-sector model

\footnotetext{
${ }^{1}$ One way to approach this problem is to assume that, on the margin, the return to agriculture workers is equal to the wage paid in the rural industry; see, e.g., Johnson and Chow (1997), and Dekle and Vandenbroucke (2010). However, such a wage rate is not a good proxy for the marginal productivity of Chinese peasants. In order to absorb excess labor from agriculture, the Chinese central government encourages local rural officials to develop township and village enterprises (TVEs), which are owned by the local rural citizens and operated by the local government. Right now, TVE employs about 138 million people. However, it is difficult to classify TVE as a marketoriented sector. Because of the fragmented labor market and official obstacles to both rural-urban and rural-rural migration, TVE contributes significantly to local employment. Due to the underdevelopment of financial institutions and the imperfect capital market, local governments use their political connections with the central banks to channel loans to TVEs; see Byrd and Gelb (1991) and Chang and Wang (1994) for more details. The strong political influence and the many other distortions mean that the rural industrial wage rate may be a poor proxy for agricultural wages in China.

2 We also estimate the labor input using a "shadow wage" approach; see, e.g., Jacoby (1993) and Skoufias (1994). The shadow-wage approach assumes the existence of a household production function that has different types of labor as distinct inputs, that is, by sex, age and education. The shadow wage of each farmer is simply the marginal product of labor, estimated using the agricultural production function. Both methods yield similar results.

${ }^{3}$ Examples of the first class of models are Matsuyama (1992), Echevarria (1997), Laitner (2000), Kongsamut et al. (2001), and Caselli and Coleman (2001). In these models, an increase in income is associated with a smaller share of spending in agricultural goods (e.g., Engel's Law). The second class of models includes Irz and Roe (2005), Ngai and Pissarides (2007), and Acemoglu and Guerrieri (2008). In these models, employment moves to the sector with the lowest productivity growth as a compensatory mechanism. The closest model to ours is that of Hayashi and Prescott (2008), which reviews patterns of Japanese economic development. They argue that the Japanese miracle did not take place before World War II because of cultural barriers that kept agricultural employment constant throughout the pre-war period. Our emphasis is on the role of differences in productivity in China.
}

that draws insights from both of these literatures. Using a calibrated version of the model, we first reproduce key patterns of the Chinese economy between 1978 and 2008. To examine the role of agriculture in China's transformation, we ask: if agricultural and non-agricultural TFP had not changed during the reform period, what would be the sectoral distribution of output and employment, and the overall and sectoral growth rates of output?

The majority of the sectoral reallocation of output and employment toward non-agricultural sectors is due to China's rapid TFP growth in agriculture. Moreover, agricultural TFP is as important as non-agricultural TFP in accounting for China's overall growth rate, and more important than non-agricultural TFP in accounting for the growth rate of the non-agricultural sector. Agricultural TFP contributes to aggregate and non-agricultural growth by reallocating workers to the non-agricultural sector, where capital accumulation takes place. This mechanism is well-known in the development literature, but it is especially important in China for two reasons. First, as much as $35 \%$ of the labor force is still in agriculture. Thus, there are still potential gains through labor reallocations. Second, Chinese physical and human capital accumulation have proceeded at rapid rates with apparently little change in the rates of return to these investments; see, e.g., Bai et al. (2006), Li et al. (2009), Song et al. (2011), and Whalley and Zhao (2010). Under these circumstances, due to the complementarity between capital and labor, a faster transfer of workers toward non-agricultural activities fosters economic growth.

\subsection{Related literature}

Sectoral reallocations out of agriculture have been a major component of the rapid growth in Taiwan and South Korea, and they characterize the modern growth experience of the majority of nations, including the U.S.; see Young (1995), Caselli and Coleman (2001), and Gollin et al. (2002). Sectoral reallocations out of and rapid productivity growth in agriculture are also typically seen as important factors in China's rapid growth. This view has been most prominently ascribed to Young (2003). According to Young (2003, p. 1260): "[d]espite the popular academic emphasis on industry and exports, a deeper understanding of the success of the world's most rapid growing economies may lie in that most fundamental of development topics: agriculture, land, and the peasant." Young (2003), however, did not go any further in the sense of actually investigating the agricultural sector. We directly confront agricultural changes.

A series of recent studies have focused on China's economic growth using a macroeconomic approach. ${ }^{4}$ An emphasis in the literature has been on reallocations between private firms and state-owned enterprises (SOEs); see, e.g., Song et al. (2011) and Dekle and Vandenbroucke (2012). Song et al. (2011) focuses on capital markets and the interplay between high-productivity private firms, with limited access to credit markets, and SOEs, which have much better access to credit. They show that this interplay is consistent with high savings rates and a trade surplus, such as is observed in China. Hsieh and Klenow (2009) also examine the role of reallocation in China. They uncovered large misallocations within manufacturing and the potential for a $50 \%$ increase in manufacturing

\footnotetext{
${ }^{4}$ There is a numerous amount of microeconomic literature on Chinese agricultura productivity. Overall, the literature has documented large positive growth rates in agricultural TFP. For example, Fan (1997) showed that agricultural productivity increased 3.9\% per annum between 1985 and 1995. Wu et al. (2001) found an increase of 3.6\% between 1990 and 1995. Jin et al. (2002) found that productivity of wheat increased by more than $20 \%$ between 1990 and 1995 . Nin-Pratt et al. (2010) showed that agricultural TFP growth in 1990s was about 4.4\%. Both Fan and Pardey (1997) and Jin et al. (2002) emphasized the importance of investment in agricultural R\&D for TFP growth. Lin (1992) and Huang and Rozelle (1996) emphasized institutional reforms as the main source of agricultural growth during the early 1980s.
} 
TFP through reallocations within the manufacturing sector. Separately, Bai et al. (2006) measure the return to capital in China, and show that while this return declined considerably between 1978 and 1998, it still remains at relatively high levels (about 20\%) despite high investment rates.

We do not provide a disaggregated analysis of the non-agricultural sector. We focus on agriculture to address the fact that there are large reallocations of labor within China; movements involving tens of millions of people. Based on that metric, China's progress in agriculture has been remarkable. As noted by Lin (1998), despite the near doubling of its population, China has been feeding itself with daily consumption of calories increasing by $73 \%$ since the late 1970s. (See also Johnson (2000, p. 319) for related remarks about Chinese agriculture.)

Finally, Dekle and Vandenbroucke's research $(2010,2012)$ share many features with the present paper. However, we devote most of our attention to measuring agricultural productivity. In this regard, we have already pointed out an important difference in our measurement of agricultural productivity with respect to Dekle and Vandenbroucke (2010); see Footnote 1. Furthermore, in our model, we abstract from changes in the SOEs and mobility frictions, aspects emphasized by Dekle and Vandenbroucke (2012). Abstracting from these elements allows us to obtain highly transparent results, as well as closed-form solutions for key variables in the model. We see both papers as complementary to ours.

\section{Background}

This section provides a brief background of China's reforms since 1978. Our focus is on agriculture and labor mobility. The references herein, Chow (2007), Lin et al. (1996), Brandt and Rawski (2008), and $\mathrm{Xu}$ (2011), provide detailed accounts of the reforms.

Before 1978, rural areas in China were severely affected by collective farming, central planning, and the orientation of development strategy toward industrialization. The Chinese government had tight control over commodity prices, and capital was mainly accumulated and concentrated in the infrastructure sector. Chinese farmers bore most of the financial burden of industrialization through the unified purchase and sale system, which maintained "price scissors" between agricultural and industrial prices. Farm products purchased at low prices mandated by the State were sold in urban areas at similarly low prices in order to minimize production costs in heavy industry; see, e.g., Wu (2003). The national household registration system (hukou) also restricted rural-urban migration by limiting access to work opportunities and social benefits for unauthorized urban workers. The hukou system, instituted in the mid-1950s, requires each person to register, reside, and work in their hukou designated location. ${ }^{5}$

Agricultural reforms in 1978 introduced a market mechanism for agricultural goods; see Lin et al. (1996). The reforms replaced the collective commune system with the household responsibility system (HRS). ${ }^{6}$ Under HRS, state-owned land was assigned to households with contracts for up to 15 years; see Lin (1992). This meant that individuals became the primary decision making units. A famous slogan stated the main principle of this reform as: "once a peasant's state

\footnotetext{
${ }^{5}$ Hukou is either rural or urban and either agricultural or non-agricultural. However, as noted by Fan (2008, p. 51), "in recent years, the distinction between agricultural hukou and non-agricultural hukou is no longer as compelling. Some provinces and large cities have, in fact, eliminated hukou classification."

${ }^{6}$ Under the commune system, people in rural areas were brought together into production teams and by law, all land and machinery were owned collectively. Work in the field was assigned to each team member. The total income of a production team was either divided equally among the members or as determined by the team leader subjectively. McMillan et al. (1989) estimated that an individual worker could be paid as little as $30 \%$ of his/her marginal product in the commune system.
}

quota and collective contribution have been fulfilled, the rest is his to dispose of as he wishes." China also implemented a dual-track price system in order to deregulate commodity prices. The weight of state-regulated prices has declined steadily; in 1999, the portion of commodities with government-determined prices was only $5 \%$ of the total output value; see Lin and Yu (2009). The effect of the agricultural reforms on output has been large. According to Lin (1992), China's crop output increased by 42\% between 1978 and 1984, with about half of that growth being accounted for by the HRS.

Institutional reforms have also reduced the degree of state control over labor mobility. Since the 1980s, local governments have been given the autonomy to administer temporary residential permits, which allow rural migrants to move about and work in cities. Additional reforms in the 1990s further relaxed the criteria for granting urban hukou in large and medium-sized cities; see Fan (2008, chapter 3).These reforms, however, have primarily benefited a select group of people (e.g., investors, property buyers, and professionals) who are allowed to purchase a blue-stamp hukou, a Chinese-style "green card." According to some analysts, the "hukou system has been weakened as a migration control tool during the reform period" although wages continue to be distorted due to limited mobility; see, e.g., Liu (2005, p. 134). Easing mobility restrictions has had a large effect on internal migration. Between 1979 and 2009, China's urban population increased by about 440 million to 622 million, with over $75 \%$ of this increase attributable to net migration and urban reclassification; see Chan (2013).

During the post-reform period, China has maintained rapid output growth and has seen a rapid reallocation of labor. GDP per capita growth exceeded 6\% between 1978 and 1998; see Young (2003). ${ }^{7}$ Further, total employment in agricultural activities has declined from $70 \%$ in 1978 to less than $40 \%$ in 2008 . The share of agricultural output has declined from $30 \%$ to $11 \%{ }^{8}$ China's urbanization rate increased from $21 \%$ in 1982 to $43 \%$ in 2006; see Fan (2008, p. 1). In 2012, China passed the 50\% urbanization point; see Chan (2012).

\section{The model economy}

We represent the Chinese economy using a two-sector neoclassical growth model with non-homothetic preferences, heterogeneous sectoral Cobb-Douglas production functions, and exogenous and heterogeneous productivity growth. ${ }^{9}$ To focus on the role of agricultural productivity, and for the sake of tractability, we assign a limited role to distortions in the output, labor, and capital markets. Using the baseline model, we briefly discuss ways to incorporate market distortions. In the measurement section, we examine the influence of controlled agricultural prices on productivity, and consider differences between inland and coastal agricultural labor markets. In the

\footnotetext{
7 There are measurement problems with the official data. Young (2003) argues that the most serious problem is the implicit GDP deflator, which relies on enterprisereported data, and systematically underestimates inflation. Using independent price indices, the annual growth rate of output in the non-agricultural sector is reduced from $7.8 \%$ to $6.1 \%$.

8 China's pre-reform national accounts were compiled based on the Material Product System (MPS). The MPS, developed by the former Soviet Union, measured output in terms of physical production therefore ignoring certain services. Official data for the pre-1978 period shows a slight change in the employment and output shares; see Brandt and Rawski (2008, p. 482).

${ }^{9}$ We study a closed-economy model. Chinese official data (CSY) indicate that in the last two decades, the value of imported agricultural goods is only about $2 \%$ of domestic production. We therefore assume a small effect of imports on food prices. Further, Yang and Zhu (2013) develop a two-sector model with trade to account for England's growth experience. In their model, which assumes exogenous world prices, the solutions with and without trade are identical. However, with trade, the subsistence level of food consumption would be reduced by the amount of imports.
} 
quantitative section, we also examine the significance of market distortions. $^{10}$

\subsection{Environment}

Time is continuous, $t \geq 0$. There is an infinitely-lived representative household with time separable and non-homothetic preferences defined over the per capita consumption of agricultural goods, $c_{a}(t)$, and non-agricultural goods, $c_{m}(t)$ :

$\int_{0}^{\infty} e^{-\rho t} u\left(c_{a}(t), c_{m}(t)\right) d t$

where $u\left(c_{a}(t), c_{m}(t)\right) \equiv \omega 1 \mathrm{n}\left(c_{a}(t)-\gamma\right)+(1-\omega) \operatorname{nn}\left(c_{m}(t)\right), \rho>0$ is the rate of time preference, $\omega$ is the utility weight of agricultural goods, and $\gamma>0$ is the "subsistence level" for agricultural consumption.

The agricultural sector produces consumption goods. Let $y_{\mathrm{a}}(t)$ denote output per capita in the agricultural sector. Output from the nonagricultural sector can be either consumed or invested. Let $y_{m}(t)$ denote output per capita in the non-agricultural sector. Production takes place with a constant return to scale Cobb-Douglas technologies. In terms of per capita quantities, these sectors are described by

$c_{a}(t)=A_{a}(t)\left[k_{a}(t)\right]^{\alpha_{a}} n_{a}(t)$, and

$\dot{k}(t)=A_{m}(t)\left[k_{m}(t)\right]^{\alpha_{m}} n_{m}(t)-c_{m}(t)-(\delta+\nu) k(t)$,

where $\delta>0$ is the depreciation rate; $v>0$ is the growth rate of the labor force; $\alpha_{i}$ is the capital share in sector $i$; $k_{i}(t)$ is the capital-labor ratio in $i ; n_{i}(t)$ is the employment share in $i$; and $n a(t)+n_{m}(t)=1$.

The aggregate capital-labor ratio, denoted by $k(t)$, satisfies

$k(t)=n_{a}(t) k_{a}(t)+n_{m}(t) k_{m}(t)$.

Technological progress is exogenous and takes place at different rates across sectors:

$\frac{\dot{A}_{i}(t)}{A_{i}(t)}=\mu_{i}$, for $i=a$ and $m$.

\subsection{Sectoral allocations}

We study the solution to a social planning problem, although we describe some of the properties of the allocation using a market economy. The social planner chooses the sequences $\left\{c_{a}(t), c_{m}(t), k_{a}(t), k_{m}(t)\right.$, $\left.n_{a}(t): t \geq 0\right\}$ in order to maximize Eq. (1) subject to the feasibility conditions, a transversality condition, and an initial value of capital, $k_{0}>0$. In this sub-section, we study the static conditions that characterize the sectoral allocation of capital and consumption. The allocation of output into consumption and capital accumulation is discussed below.

\footnotetext{
${ }^{10}$ Analyses of how pre-reform distortions came to exist or changed, and of how new distortions emerged during the post-reform period, are beyond the scope of this paper. Sah and Stiglitz (1984) studied "price scissors." Page: 13Lin and Yu (2009) estimated Sah and Stiglitz's (1984) model using Chinese data. An analysis along the lines of Sah and Stiglitz (1984) requires, at a minimum, a framework that incorporates rural and urban markets, as well as markets for agricultural and non-agricultural goods. The measurement of market distortions is also beyond the scope of this paper. Brandt et al. (2008) inferred distortions from Chinese sectoral data, and found little systematic change in the implied distortions between 1978 and 2000. Hsieh and Klenow (2009) measured the importance of output and labor market distortions in China, but only within manufacturing. Young (2000) argued that during the reform period, local governments implemented a variety of interregional barriers to trade that led to higher market fragmentation. Young (2000) provided supportive evidence for higher distortions using provincial and sectoral dispersion measures for price and output data. Holz (2009) questioned Young's results and instead argued that dispersion in China is within the range of a relatively integrated large economy, such as that of the U.S.
}

The sectoral allocation of capital per capita is chosen to equalize the marginal rates of transformation across sectors, so that

$k_{a}(t)=B k_{m}(t)$,

where $\mathrm{B} \equiv \alpha_{a}\left(1-\alpha_{m}\right) / \alpha_{m}\left(1-\alpha_{a}\right)$. Since capital-labor ratios are proportional across sectors, Eqs. (4) and (5) imply that

$k(t)=\left[(B-1) n_{a}(t)+1\right] k_{m}(t)$.

The sectoral allocation of consumption equalizes the marginal rate of substitution to the marginal rate of transformation. In a competitive economy, this common value equals the relative price of agricultural goods, denoted by $p(t)$ :

$\frac{\omega}{1-\omega}\left(\frac{c_{m}(t)}{c_{a}(t)-\gamma}\right)=p(t)=D\left(\frac{A_{m}(t)}{A_{a}(t)}\right)\left[k_{m}(t)\right]^{\alpha_{m}-\alpha_{a}}$,

where $D \equiv\left(\alpha_{m} / \alpha_{a}\right)^{\alpha_{a}}\left(\left(1-\alpha_{m}\right) /\left(1-\alpha_{a}\right)\right)^{1-\alpha_{a}} \cdot{ }^{11}$

\subsection{Sources of structural change}

Based on Eq. (7), we can discuss structural changes in the share of expenditures on agricultural goods relative to total expenditures. Let $c(t) \equiv p(t) c_{a}(t)+c_{m}(t)$ denote the aggregate consumption expenditure, and let $\Psi a(t)$ denote the share of total expenditures on agricultural goods,

$\psi_{a}(t) \equiv \frac{p(t) c_{a}(t)}{c(t)}=\omega+(1-\omega) \frac{p(t) \gamma}{c(t)}$

The share $\Psi_{a}(t)$ declines if $p(t)$ declines or if $c(t)$ increases. With $\gamma>0$, the demand for agricultural goods is price-inelastic and has an income elasticity less than one. Thus, if the increase in the growth rate of agricultural productivity (relative to non-agricultural productivity) is faster that the increase in capital intensity in the non-agricultural sector (provided that $\alpha_{m}>\alpha_{a}$ ), agricultural prices will decline; see Eq. (7). With price-inelastic demands, the share $\Psi_{a}(t)$ declines. ${ }^{12}$ If the sectoral production functions are identical and the sectoral productivities are equal, then agricultural prices will satisfy $p(t)=D$ for $t \geq 0$; see Eq. (7). As $c(t)$ increases, however, the share $\Psi_{a}(t)$ declines due to income effects; see Eq. (8).

We can also study changes in sectoral output. Let $y(t) \equiv p(t)$ $y_{a}(t)+y_{m}(t)$ denote aggregate output, and let $\theta a(t)$ denote the output share in agriculture,

$\theta_{a}(t) \equiv \frac{p(t) y_{a}(t)}{y(t)}=\frac{F n_{a}(t)}{1-n_{a}(t)}$

where $F \equiv D B^{\alpha_{m}}$. As expected, the output share $\theta_{a}(t)$ is increasing in $n_{a}(t)$.

\subsection{Market distortions}

In the above analysis, there are no distortions in the economy. In order to discuss the role of sector-specific distortions, let $(p(t), w(t)$, $r(t))$ denote respectively the undistorted price, the undistorted wage,

\footnotetext{
11 A competitive equilibrium is standard. Let $(p, w, r)$ denote respectively the price of agricultural goods, the market wage, and the rental price of capital with non-agricultural goods as the numeraire. In a competitive market economy, (i) the representative firms' profits are $\Pi_{i}=\max _{k_{i}, n_{i}}\left\{p_{i} A_{i}\left[k_{i}\right]^{\alpha_{i}} n_{i}-r k_{i} n_{i}-w n_{i}\right\}$, with $i=a$ and $m, p_{a} \equiv p$, and $p_{m} \equiv 1$; (ii) the representative household maximizes Eq. (1) subject to $k+p c_{a}+c_{m}=(r-\delta-v) k+w$ and (iii) markets clear; that is, $n_{a}+n_{m}=1$ and Eq. (4) holds. In the absence of distortions, the competitive equilibrium and the social planner allocation coincide.

12 Non-homothetic preferences are not necessary for the price effects just discussed. Ngai and Pissarides (2007) considered isoelastic preferences with an elasticity of substitution different from one. Under these general preferences, an asymptotic closedform solution is possible only if $\alpha_{a}+\alpha_{m}$.
} 
and the undistorted rental price of capital with non-agricultural goods as the numeraire. Let $\tau_{p}^{i}$ and $\tau_{n}^{i}$ denote price and labor market distortions for sector $i=a$ and $m$. Distortions in capital markets can be mapped into $\tau_{p, n}^{i}$. Due to distortions $\tau_{p, n}^{a}$, the representative firm in the agricultural sector faces a distorted price and a distorted wage, given by $p(t)\left(1-\tau_{p}^{a}\right)$ and $w(t)\left(1+\tau_{n}^{a}\right)$, respectively. The representative firm in the non-agricultural sector faces similar sector-specific prices.

Profit maximization implies that capital-labor ratios are still proportional across sectors, as in Eq. (5). The proportionality factor incorporates labor market distortions,

$B \equiv \frac{\alpha_{a}\left(1-\alpha_{m}\right)}{\left(1-\alpha_{a}\right) \alpha_{m}} \frac{1+\tau_{n}^{a}}{1+\tau_{n}^{m}}$

The sectoral allocation of consumption is the same as before. The right-hand side of Eq. (7) is

$p(t)=D\left(\frac{A_{m}(t)}{A_{a}(t)}\right)\left(\frac{1-\tau_{p}^{m}}{1-\tau_{p}^{a}}\right)\left(\frac{1+\tau_{n}^{a}}{1+\tau_{n}^{m}}\right)^{1-\alpha_{m}}\left[k_{m}(t)\right]^{\alpha_{m}-\alpha_{a}}$.

Changes in distortions, either across markets or across sectors, are an added source of structural changes in Eq. (8). Distortions are a reduced-form way to capture state intervention. For example, distortions that favor the use of capital in the non-agricultural sector and seek to depress the relative price of agricultural goods can be attained by setting $\tau_{p, n}^{i}$ appropriately. Brandt et al. (2008) contain several illustrations of how these distortions capture policy interventions in China.

It is possible to infer the distortions $\tau_{p, n}^{i}$ from the data. With that purpose, Brandt et al. (2008) studied changes in the relative price $p(t)$, the relative capital-labor ratio $k_{m}(t) / k_{a}(t)$, and the relative labor compensation across sectors in China. Overall, they found little evidence of long run trends in the distortions between 1978 and $2000 .{ }^{13}$ If the distortions are time-invariant, it is possible to treat $\tau_{p, n}^{i}$ as part of measured sectoral productivities, $A_{i}(t)$. For instance, let $A_{i}(t) \equiv \tilde{A}_{i}(t)\left(1-\tau_{p}^{i}\right)\left(1+\tau_{n}^{i}\right)^{\alpha_{m}-1}$. The price implications of an undistorted model with sectoral productivities $A_{i}(t)$ are the same as those of a distorted model with baseline productivity $\tilde{A}_{i}(t)$.

\subsection{The dynamical system}

In the context of an undistorted model, the allocation between consumption and capital accumulation for non-agricultural goods satisfies the standard Euler equation:

$\frac{\dot{c}_{m}(t)}{c_{m}(t)}=\alpha_{m} A_{m}(t)\left[k_{m}(t)\right]^{\alpha_{m}-1}-(\delta+\rho+\nu)$.

The solution to the social planner problem satisfies two differential equations, Eqs. (3) and (12), and three static equations, Eqs. (2), (6), and (7).

We are interested in the transitional phase. When $c_{a}(t)$ and $c_{m}(t)$ grow over time, however, $\gamma$ becomes unimportant for the allocation as preferences are homothetic asymptotically. With homothetic preferences, the model can be fully characterized without agricultural productivity having a direct role. As $\gamma \rightarrow 0$, Eqs. (2) and (7) yield

$c_{m}(t)=E A_{m}(t)\left[k_{m}(t)\right]^{a_{m}} n_{a}(t)$,

\footnotetext{
13 Brandt et al. (2008) found a slight decline in the relative price $p(t)$, little evidence of long run trends in the relative capital-labor ratios in the two sectors, and a fall in labor market distortions in the non-agricultural sector, but only during the initial years of reform. They interpreted these findings as indicative of improvements in nonagricultural TFP relative to agricultural TFP. One of our quantitative exercises examines the role of improvements in non-agricultural TFP.
}

where $E \equiv(1-\omega)\left(1-\alpha_{m}\right) / \omega\left(1-\alpha_{a}\right)$, which is a decreasing function of the utility weight of the agricultural good, $\omega$. We omit the time index for simplicity's sake, and normalize the consumption of non-agricultural goods and capital goods in terms of nonagricultural productivity: $\hat{k} \equiv k A_{m}^{-1 /\left(1-\alpha_{m}\right)}, \hat{k}_{m} \equiv k_{m} A_{m}^{-1 /\left(1-\alpha_{m}\right)}$, and $\hat{c}_{m} \equiv$ $c_{m} A_{m}^{-1 /\left(1-\alpha_{m}\right)}$. If we let $g_{m} \equiv \mu_{m} /\left(1-\alpha_{m}\right)$, then the state of the economy evolves according to

$\frac{\dot{\hat{c}}_{m}}{\hat{c}_{m}}=\alpha_{m}\left[\hat{k}_{m}\right]^{\alpha_{m}-1}-\left(\delta+\rho+\nu+g_{m}\right)$, and

$\dot{\hat{k}}=\left[\hat{k}_{m}\right]^{\alpha_{m}}\left(1-n_{a}\right)-\hat{c}_{m}-\left(\delta+\nu+g_{m}\right) \hat{k}$.

\subsection{Steady state}

Let $\left({ }^{*}\right)$ indicate steady state values. From Eq. (14), we obtain $\hat{k}_{m}^{*}$ :

$\alpha_{m}\left[\hat{k}_{m}^{*}\right]^{\alpha_{m}-1}=\delta+\rho+\nu+g_{m}$.

In the steady state, the employment share in agriculture remains constant. Substituting Eqs. (6) and (13) into Eq. (15) yields

$n_{a}^{*}=\frac{\left[\hat{k}_{m}^{*}\right]^{\alpha_{m}-1}-\left(\delta+\nu+g_{m}\right)}{\left[\hat{k}_{m}^{*}\right]^{\alpha_{m}-1}(1+E)+\left(\delta+\nu+g_{m}\right)(B-1)}$.

The values of $\hat{c}_{m}^{*}$ and $\hat{k}^{*}$ follow from the static conditions. Given $n_{a}^{*}$, and $k_{m}^{*}(t) \equiv \hat{k}_{m}^{*} A_{m}(t)^{1 /\left(1-\alpha_{m}\right)}$, Eq. (5) determines $k_{a}^{*}(t)$. Both capitals grow at a constant rate determined by $\mu_{m}$. These values, together with $A_{a}(t)$, determine the consumption of the agricultural good, $c_{a}^{*}(t)$, and its relative price, $p^{*}(t)$. The share of expenditures on agricultural goods is $\psi_{a}^{*}=\omega$; see Eq. (8), and the output share in agriculture $\theta_{a}^{*}$ is constant and determined by $n_{a}^{*}$; see Eq. (9).

Growth is non-balanced because the outputs in the two sectors grow at different rates. Notice also that $\gamma>0$ is only important during the transitional phase. During the transition, sectoral capital and output depend on agricultural productivity. We solve for the transitional phase numerically so as to investigate this interdependence.

\section{Productivity growth in Chinese agriculture}

We need agricultural and non-agricultural productivity growth to simulate the model. We rely on Young (2003) for estimates of $\mu_{m}$, and provide our own estimates of $\mu_{a}$.

In order to estimate agricultural TFP, we pay considerable attention to the analysis of the labor input. The methodology is standard; see, e.g., Jorgenson et al. (1987) and Young (2003). We assume that the labor input can be viewed as a constant return to scale function $G(\cdot)$ with $N$ "types" of labor: $L=G\left(L_{1}, L_{2}, \ldots, L_{N}\right)$. Each labor type is differentiated by age, gender, and educational background, so each has its own specific marginal productivity. An index for the aggregate labor input is a weighted average of the different types of labor with weights given by the shares of earnings on total compensation. The change in the labor input is:

$\frac{d L}{L}=\sum_{i=1}^{N} s_{i}\left(\frac{d L_{i}}{L_{i}}\right)$, where $s_{i} \equiv \frac{d G\left(L_{1}, \ldots, L_{N}\right)}{d L_{i}} \frac{L_{i}}{G(\cdot)}$.

Under the assumption of competitive markets, we can equate $d G\left(L_{1}, \ldots, L_{N}\right) / d L_{i}$ to $w_{i}$, which is the wage for labor type $i$. By construction, the index $L$ places greater weight on the growth of groups with higher relative wages. 


\subsection{Data}

We use longitudinal data from the China Health and Nutrition Survey (CHNS), which is conducted by the Carolina Population Center at the University of North Carolina at Chapel Hill. The survey includes eight waves (1989, 1991, 1993, 1997, 2000, 2004, 2006, and 2009), and covers nine provinces along the coast, and in the northeast, middle, and west of China. ${ }^{14}$ The analysis here is restricted to data from samples of rural areas from 1991 to 2009. The questions asked in the 1989 survey are different from those asked in the rest of the sequence, and it is difficult to consistently compare the data for 1989 to that from the other years. Our final sample size consists of 3689 households and 29,413 individual observations.

The CHNS allows us to determine individual incomes and the time allocation in agriculture. Individual income is defined as the sum of net revenue in a given year from all agricultural production activities. ${ }^{15}$ Individual income adds each person's income source and is not based on a simple even division of household income between household members. ${ }^{16}$ To measure the number of hours worked, participating individuals were asked three questions related to their labor input for each agricultural activity: how many hours they worked per day; how many days they worked per week; and how many months they worked per year. Using these questions, we compute an individual's working hours per survey year. Our measure of individual wages in agriculture divides total annual income by the total number of hours worked. That is, our benchmark measure of individual wages is the average product of labor. Later in this section we discuss estimates of the marginal product of labor based on a "shadow wage" approach. Both approaches yield virtually the same implications for agricultural productivity.

We cross-classify the labor input into three factors: sex (s), age (a) and education (e). We distinguish the labor input according to 88 $(2 \times 11 \times 4)$ categories. Table 1 shows the distribution of the working population across sex, age, and education. As the table demonstrates, educational attainment has improved in China. The fraction of the rural working population without any formal education, for example, has declined from $26 \%$ in 1991 to $15 \%$ in 2009. This suggests an improvement in the quality of labor in agriculture. Likewise, people aged 50 or above accounted for $22 \%$ of the working population in 1991 . In 2009 , this number went up to above $50 \%$. This indicates a migration trend from rural to urban areas among the younger generation. $^{17}$

\footnotetext{
${ }^{14}$ Initiated in 1989, the CHNS was designed as a time-cohort survey; it covers Heilongjiang, Liaoning, Shandong, Jiangsu, Henan, Hubei, Hunan, Guangxi, and Guizhou. A multistage, random cluster-sampling scheme is used to draw a sample from each province. In particular, counties in the nine provinces were stratified by income, after which four counties from each province were selected using a weighted method. Villages and townships in the counties, as well as urban and suburban neighborhoods in the cities, were randomly selected.

${ }^{15}$ Individual income is derived from farming, fishing, gardening, and raising livestock. The calculation for income is similar for all activities. For example, for farming income, the head of the household would provide: the value of sale of farming products, the value of consumed farming products, and the expense on farming products. Net household farming income is calculated as the value of sales from farming plus the value of consumed farming product minus farming expenses. Each household member reports the hours spent farming. Consequently, individual farming income is the individual proportion of net household farming income, where the proportion is determined by the share of time spent farming.

${ }^{16}$ Imputation for missing individual data is sometimes made if a filter variable indicates certain agricultural activities for an individual. Imputation of income is based on the household mean, the mean of individuals in the community, or the mean of the city, in order of availability. We control for income imputation in all our estimates. 17 In order to verify the validity of the CHNS, we examined the distribution of the rural population in the 2000 census. The composition of the population in the CHNS is similar to that in the census. The fraction of males in the census is 0.51 , while in the CHNS in 2000, it is 0.49 . The distribution of education in the census according to the categories of Table 1 is $0.14,0.38,0.40$, and 0.07 . The main difference with the CHNS in 2000 is at the tertiary level of education. The values in the 2000 census are very similar to those of later CHNS waves.
}

Table 1

Distribution of the agricultural working population by sex, age, and education. Source: China Health and Nutrition Survey (CHNS).

\begin{tabular}{|c|c|c|c|c|c|c|c|}
\hline & 1991 & 1993 & 1997 & 2000 & 2004 & 2006 & 2009 \\
\hline \multicolumn{8}{|l|}{ A. Sex } \\
\hline Male & 0.46 & 0.46 & 0.48 & 0.47 & 0.48 & 0.45 & 0.46 \\
\hline Female & 0.54 & 0.54 & 0.52 & 0.53 & 0.52 & 0.55 & 0.53 \\
\hline \multicolumn{8}{|c|}{ B. Educational attainment } \\
\hline None & 0.26 & 0.24 & 0.20 & 0.17 & 0.17 & 0.17 & 0.15 \\
\hline Primary & 0.39 & 0.38 & 0.39 & 0.38 & 0.42 & 0.40 & 0.41 \\
\hline Secondary & 0.27 & 0.28 & 0.29 & 0.30 & 0.35 & 0.34 & 0.37 \\
\hline Tertiary & 0.08 & 0.10 & 0.11 & 0.15 & 0.09 & 0.10 & 0.07 \\
\hline \multicolumn{8}{|l|}{ C. Age group } \\
\hline$<20$ & 0.09 & 0.07 & 0.05 & 0.04 & 0.04 & 0.04 & 0.03 \\
\hline $20-24$ & 0.11 & 0.09 & 0.08 & 0.05 & 0.03 & 0.01 & 0.02 \\
\hline $25-29$ & 0.13 & 0.10 & 0.10 & 0.08 & 0.05 & 0.03 & 0.03 \\
\hline $30-34$ & 0.10 & 0.11 & 0.12 & 0.11 & 0.08 & 0.07 & 0.05 \\
\hline $35-39$ & 0.14 & 0.13 & 0.09 & 0.13 & 0.11 & 0.11 & 0.10 \\
\hline $40-44$ & 0.12 & 0.14 & 0.14 & 0.11 & 0.12 & 0.15 & 0.13 \\
\hline $45-49$ & 0.09 & 0.11 & 0.14 & 0.15 & 0.13 & 0.10 & 0.13 \\
\hline $50-54$ & 0.07 & 0.07 & 0.10 & 0.12 & 0.15 & 0.16 & 0.13 \\
\hline $55-59$ & 0.06 & 0.06 & 0.06 & 0.08 & 0.12 & 0.13 & 0.14 \\
\hline $60-64$ & 0.04 & 0.05 & 0.05 & 0.06 & 0.07 & 0.09 & 0.12 \\
\hline$\geq 65$ & 0.05 & 0.06 & 0.06 & 0.07 & 0.10 & 0.12 & 0.14 \\
\hline Sample size & 5389 & 4616 & 4656 & 4409 & 3672 & 3226 & 3445 \\
\hline
\end{tabular}

Notes. - None: no formal education; Primary: 1-6 years of education; Secondary: $6-9$ years of education; Tertiary: $>9$ years of education.

\subsection{Log-wage profiles}

We regress the $\log$ (income/hours) on indicator variables for sex, education, and age. We control for marital status and include an indicator if the value of the individual's income is imputed. We report OLS estimates as well as estimates that control for individual fixed effects. For all specifications, we include a time control. There is a small number of instances in the survey featuring negative wages; we exclude these individuals. ${ }^{18}$

Table 2 displays the resulting wage estimates by age, sex, and education in China's agricultural sector from 1991 to 2009. Column (1) presents the pooled OLS estimates. In column (2), we investigate whether our wage profile changes when including individual fixed effects controls. In columns (3) and (4), we separate our sample into coastal and inland provinces in order to examine regional differences in returns to age, education, and gender. Finally, in column (5), we reproduce the log-wage profile of non-agricultural workers in 1986 from Young (2003, Table 17). We use Young (2003) in an indirect way to examine the validity of our estimates.

The age profiles are consistent across specifications. In rural China, wages rise with educational attainment, but at a slower rate than in the non-agricultural sector. Similarly, the age-income profile follows an inverted U-shape pattern. In specification (1), which is closer conceptually to specification (5), wages peak at ages 35-39 for agricultural populations. In specification (2), wages peak at ages 60-65. In the non-agricultural sector (column (5)), the peak is for the age group 50-54. Finally, specification (1) suggests that there is no difference between the wages of men and women in the agricultural sector. Young (2003), however, suggests that women earn lower non-agricultural wages than men.

\footnotetext{
18 Dropping individuals with negative incomes reduces our sample size to 28,062 individual observations. In some instances, individuals report negative income and this leads to negative wages. Due to the cyclical nature of agriculture (e.g., unavoidable fluctuations in prices and weather), individuals report expenses at the beginning of the year that exceed sales at the end of the year. Slightly less than $5 \%$ of our sample have negative wages. About $16 \%$ of households reported more expenses than sales of livestock in our sample. We implemented various methods to impute positive wages. For example, we replaced the negative wages with the lowest positive wage in the community. These results are virtually identical to those in Table 2 , and are available upon request.
} 
Table 2

Estimated log-wage profiles by worker characteristics (relative to the base group).

\begin{tabular}{|c|c|c|c|c|c|}
\hline \multicolumn{6}{|c|}{ Dependent variable: log(income/hours) } \\
\hline & \multicolumn{4}{|c|}{ Data: CHNS } & \multirow{2}{*}{$\begin{array}{l}\text { Estimates in } \\
\text { Young (2003) }\end{array}$} \\
\hline & OLS & Fixed effects & OLS: Coast & OLS: Inland & \\
\hline & (1) & (2) & (3) & (4) & (5) \\
\hline \multicolumn{6}{|c|}{ A. Educational attainment } \\
\hline None & $\begin{array}{l}-0.170 \\
(0.045)\end{array}$ & $\begin{array}{l}-0.116 \\
(0.071)\end{array}$ & $\begin{array}{l}-0.143 \\
(0.070)\end{array}$ & $\begin{array}{l}-0.220 \\
(0.059)\end{array}$ & $\begin{array}{l}-0.32 \\
(0.022)\end{array}$ \\
\hline Primary & Base & Base & Base & Base & Base \\
\hline Secondary & $\begin{array}{l}0.085 \\
(0.039)\end{array}$ & $\begin{array}{l}0.122 \\
(0.069)\end{array}$ & $\begin{array}{l}0.059 \\
(0.060)\end{array}$ & $\begin{array}{l}0.109 \\
(0.053)\end{array}$ & $\begin{array}{l}0.16 \\
(0.008)\end{array}$ \\
\hline Tertiary & $\begin{array}{l}0.227 \\
(0.059)\end{array}$ & $\begin{array}{l}0.157 \\
(0.103)\end{array}$ & $\begin{array}{l}0.175 \\
(0.092)\end{array}$ & $\begin{array}{l}0.266 \\
(0.077)\end{array}$ & $\begin{array}{l}0.25 \\
(0.010)\end{array}$ \\
\hline \multicolumn{6}{|c|}{ B. Age group } \\
\hline$<20$ & $\begin{array}{l}0.072 \\
(0.080)\end{array}$ & $\begin{array}{l}0.286 \\
(0.149)\end{array}$ & $\begin{array}{l}-0.114 \\
(0.135)\end{array}$ & $\begin{array}{l}0.172 \\
(0.100)\end{array}$ & $\begin{array}{l}-0.25 \\
(0.014)\end{array}$ \\
\hline $20-24$ & Base & Base & Base & Base & Base \\
\hline $25-29$ & $\begin{array}{l}0.326 \\
(0.076)\end{array}$ & $\begin{array}{l}0.282 \\
(0.122)\end{array}$ & $\begin{array}{l}0.393 \\
(0.125)\end{array}$ & $\begin{array}{l}0.289 \\
(0.095)\end{array}$ & $\begin{array}{l}0.30 \\
(0.010)\end{array}$ \\
\hline $30-34$ & $\begin{array}{l}0.445 \\
(0.076)\end{array}$ & $\begin{array}{l}0.233 \\
(0.140)\end{array}$ & $\begin{array}{l}0.330 \\
(0.123)\end{array}$ & $\begin{array}{l}0.556 \\
(0.099)\end{array}$ & $\begin{array}{l}0.49 \\
(0.009)\end{array}$ \\
\hline $35-39$ & $\begin{array}{l}0.625 \\
(0.073)\end{array}$ & $\begin{array}{l}0.454 \\
(0.156)\end{array}$ & $\begin{array}{l}0.586 \\
(0.119)\end{array}$ & $\begin{array}{l}0.659 \\
(0.093)\end{array}$ & $\begin{array}{l}0.54 \\
(0.009)\end{array}$ \\
\hline $40-44$ & $\begin{array}{l}0.621 \\
(0.073)\end{array}$ & $\begin{array}{l}0.515 \\
(0.173)\end{array}$ & $\begin{array}{l}0.437 \\
(0.120)\end{array}$ & $\begin{array}{l}0.771 \\
(0.093)\end{array}$ & $\begin{array}{l}0.58 \\
(0.009)\end{array}$ \\
\hline $45-49$ & $\begin{array}{l}0.501 \\
(0.076)\end{array}$ & $\begin{array}{l}0.586 \\
(0.191)\end{array}$ & $\begin{array}{l}0.434 \\
(0.124)\end{array}$ & $\begin{array}{l}0.568 \\
(0.098)\end{array}$ & $\begin{array}{l}0.66 \\
(0.010)\end{array}$ \\
\hline $50-54$ & $\begin{array}{l}0.423 \\
(0.082)\end{array}$ & $\begin{array}{l}0.651 \\
(0.211)\end{array}$ & $\begin{array}{l}0.168 \\
(0.133)\end{array}$ & $\begin{array}{l}0.621 \\
(0.104)\end{array}$ & $\begin{array}{l}0.71 \\
(0.011)\end{array}$ \\
\hline $55-59$ & $\begin{array}{l}0.248 \\
(0.087)\end{array}$ & $\begin{array}{l}0.650 \\
(0.231)\end{array}$ & $\begin{array}{l}0.132 \\
(0.142)\end{array}$ & $\begin{array}{l}0.363 \\
(0.111)\end{array}$ & $\begin{array}{l}0.67 \\
(0.014)\end{array}$ \\
\hline $60-64$ & $\begin{array}{l}0.346 \\
(0.094)\end{array}$ & $\begin{array}{l}1.034 \\
(0.249)\end{array}$ & $\begin{array}{l}0.0630 \\
(0.150)\end{array}$ & $\begin{array}{l}0.584 \\
(0.121)\end{array}$ & $\begin{array}{l}0.60 \\
(0.023)\end{array}$ \\
\hline$\geq 65$ & $\begin{array}{l}0.098 \\
(0.090)\end{array}$ & $\begin{array}{l}0.338 \\
(0.261)\end{array}$ & $\begin{array}{l}-0.118 \\
(0.143)\end{array}$ & $\begin{array}{l}0.276 \\
(0.119)\end{array}$ & $\begin{array}{l}0.55 \\
(0.033)\end{array}$ \\
\hline \multicolumn{6}{|l|}{ C. Sex } \\
\hline Male & Base & - & Base & Base & Base \\
\hline Female & $\begin{array}{l}0.041 \\
(0.032)\end{array}$ & $\begin{array}{l}- \\
-\end{array}$ & $\begin{array}{l}-0.101 \\
(0.051)\end{array}$ & $\begin{array}{l}0.156 \\
(0.043)\end{array}$ & $\begin{array}{l}-0.12 \\
(0.005)\end{array}$ \\
\hline N. Obs. & 28,062 & 28,062 & 11,466 & 16,596 & 222,281 \\
\hline $\mathrm{R}^{2}$ & 0.21 & 0.19 & 0.22 & 0.21 & 0.83 \\
\hline
\end{tabular}

Note. - Standard errors in parentheses. See Table 1 for definitions of educational groups. Young (2003) indicates the log-wage estimates for non-agricultural workers in 1986. All specifications include time controls. The coastal provinces are Liaoning, Jiangsu, Shandong, and Guangxi. The inland provinces are Heilongjiang, Henan, Hubei, Hunan, and Guizhou.

\subsubsection{Regional differences}

Columns (3) and (4) show important differences in the return to education for coastal versus inland rural provinces. Wages rise with educational attainment at faster rates in the rural inland provinces. The higher returns to education in the inland areas imply that human capital investments in these relatively poorer areas can reduce regional inequalities. ${ }^{19}$ For the age-income profiles, both coastal and inland areas show an inverse U-shape, but the peak is higher for the inland provinces. Interestingly, agricultural wages for women are lower than men's wages in the coastal areas. The differences between coastal and inland rural provinces explain the lack of wage differences between men and women in the full sample (column (1)).

\footnotetext{
19 Fleisher et al. (2010) have indeed showed that human capital has reduced regional inequalities in China. Whalley and Zhao (2010) draw a similar conclusion for the period 1978 through 2008. In their study, human capital contributes $38 \%$ to China's economic growth. Finally, Li et al. (2009) estimate that human capital in China has increased by almost 4 times from 1985 to 2007. The growth rate of human capital accumulation has accelerated to $7.5 \%$ per year since 1995 . They suggest that this high growth rate is primarily due to an increase in educational attainment.
}

We will later use the estimates in columns (3) and (4) as an indirect way to examine the importance of labor market distortions. The idea is that with perfect labor mobility, the rates of return for age, education, and gender in the different rural regions would tend to be equalized. Instead, in our sample, agricultural wages in the rural coastal provinces are about $20 \%$ higher than those in rural inland provinces. These differences are partly due to a policy that was favorable to the coastal provinces during the early stage of the reform as well as to the better access they enjoy to global markets. As discussed in the background section, the restriction on labor mobility and factor allocation imposed by the hukou system also contributes to inequalities across regions, in particular, to rural-urban inequality; see, e.g., Liu (2005). ${ }^{20}$ Our objective is not to identify the impact of labor mobility restrictions on China's structural changes. However, since rural coastal areas are likely to be better integrated, it is possible to measure the agricultural labor input using the coefficients from the coastal and inland provinces separately. The difference in the estimates of the respective labor inputs will be due in part to factor market distortions.

\subsubsection{Price distortions}

We also measure the influence of price distortions directly. CHNS collects information in the community-level survey about ration coupon prices and free market prices for agricultural goods from 1991 to 1997. To examine the importance of price distortions, we augment the log-wage profiles to include state ration coupon prices for rice, as well as the difference between state ration prices and free market prices. $^{21}$

We focus on the influence of price distortions on the log-wage profiles. In China, as argued by Young (2003, p. 1260), "agriculture remains distorted in many respects (e.g., with local procurement and price controls)." Moreover, as noted by Young (2000, p. 1114), prices across China's provinces "have gone through bouts of falling and rising dispersion." Young (2000) interpreted this lack of convergence as evidence of higher interregional distortions. Holz (2009, p. $604)$, however, argues that "the observed patterns in price dispersion are perfectly well explained by institutional changes." Although it is virtually impossible to examine the effects of all existing distortions, including controlled prices or differences with respect to market prices, provide a direct measure of the local (dis)incentives facing farmers.

Our econometric estimates are available upon request. Due to data limitations, the data used to examine price distortions include only the 1991, 1993, and 1997 waves. The sample size is 5592 observations. We find that price distortions influence the level of log-wages. For example, a 1 yuan increase in the ration coupon price of rice in a community increases individual wages by about $9.64 \%$; the implied elasticity is 0.083 . Log-wages also increase as the gap between state prices and free market prices widens. There are, however, no significant differences in the sex-age-education wage profiles if we include state prices or the price differential as control variables.

To provide further evidence of the impact of price distortions, we interact the ration coupon price of rice with the sex-age-education indicators. The interaction terms capture the effect of price controls on the slope of the wage profiles. We display the results graphically. Figs. 1 and 2 plot the log-wage profiles by age and education categories for four specifications: (i) our baseline estimates obtained from

\footnotetext{
${ }^{20}$ Liu (2005) examined paired urban and rural communities in Beijing and showed that an urban hukou raises a person's income by about $26 \%$. In our quantitative section, we examine numerically the role of labor barriers to mobility.

21 The analyses in this subsection use confidential data. We focus on price distortions for rice based on its importance in China. Our results, however, are consistent if we include other commodities, whose prices are also controlled by the state. The sample sizes for additional commodities are reduced because price controls are less prevalent. These results are available upon request. We use pre-2000 data, because after 2000 , most commodity prices have been determined by market forces.
} 


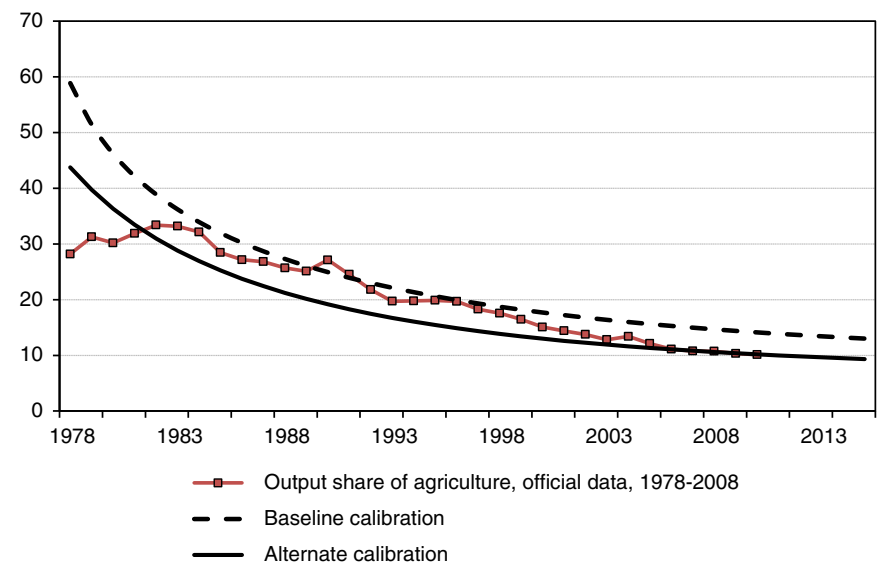

Fig. 1. Agricultural log-wage by age group with and without state controlled prices.

the entire sample (Table 2, column (1)); (ii) the log-wage profile in our reduced sample without state prices as control (so as to demonstrate that our subsample is representative); (iii) the log-wage profile when state prices are included as controls; and (iv) the log-wage profile when the interactions between state prices and the sexage-education indicators are added as controls.

Figs. 1 and 2 show that the age and education profiles are similar across specifications. The main differences in the figures are due to a small number of observations for individuals ages 60 and above, and for individuals with tertiary education. In general, since the log-wage profiles are virtually unchanged, the first-order effect of price distortions appears to be a uniform shift in the level of log-wages. This overall change in wages is consistent with the idea that distortions have a "level effect" on measured productivity.

\subsubsection{Shadow wages}

The previous estimates rely on the average product of labor. We also estimate the marginal product of agricultural labor using a "shadow wage" approach; see, e.g., Jacoby (1993) and Skoufias (1994). We present these results in the Appendix A since they are not central to the paper. We estimate a Cobb-Douglas production function and use the resulting marginal product estimates as the wages for the different labor types. To the extent that we use a Cobb-Douglas production function, the marginal and average product of labor are proportional. The implications of this approach for the labor input and productivity are presented below.

\subsection{Labor input}

Given the previous log-wage estimates, we next derive our estimate of the labor input in agriculture. Eq. (18) defines the growth rate of a
Divisia index of labor input (Hulten, 1973). The discrete approximation of Eq. (18) is given by:

$\Delta \ln L=\sum_{i=1}^{N} \bar{s}_{i} \Delta \ln H_{i}$

with $N=88$ types of labor; $H_{i}$ is the quantity of labor input in terms of total hours worked for type $i ; \bar{s}_{i} \equiv \frac{1}{2}\left(s_{i, t}+s_{i, t-1}\right)$, where $s_{i, t}$ is labor $i$ 's share of total wage compensations at time $t$; and $\Delta$ denotes the first time differences, as in $\Delta \ln L_{t} \equiv \ln L_{t}-\ln L_{t-1}$. The unweighted sum of total hours worked is $H_{t}=\sum_{i} H_{i, t}$, and the quality of labor, $Q_{t}$, is given by $L_{t}=Q_{t} H_{t}$. Expression (19) implies that $\Delta \ln Q=\Delta \ln L-\Delta \ln H$, with

$\Delta \ln Q=\sum_{i=1}^{N} \bar{s}_{i} \Delta \ln d_{i}$

where $d_{i, t}=H_{i, t} / H_{t}$ is the proportion of hours worked by type of labor. The variable $\Delta \ln Q$ measures changes in the composition of hours worked based on sex, age, and education.

To compute the growth rates defined above, we need to compile data on hours worked and labor compensation. The latter is based on the estimated log-wage profiles. To obtain average hours worked for each type of labor, we rely on the CHNS data. Finally, the employment for each category is calculated by multiplying the categorical distribution of the labor force from the CHNS (summarized in Table 1) and the aggregate agricultural employment data from the China Statistical Yearbook (Various years).

Table 3 presents the main results of this analysis. Our estimates presented here are based on specifications (1)-(4) from Table 2. We also include the resulting change in the labor input using our "shadow wage" approach.

Overall, Table 3 suggests that the labor input in agriculture decreased at an average annual rate of 4.5-5.5\%. In comparison, Young (2003) finds that the growth rate of the labor input in non-agriculture between 1978 and 1998 was about 2.6\% per year. Moreover, the quality of labor is, on average, increasing at a lower rate than Young's (2003) estimate for the quality of non-agricultural workers for 1978 through 1998 (1.1\% per year). The difference in the quality of labor between agriculture and non-agriculture shows that there are important compositional changes in employment and hours worked for those workers leaving versus those staying in agriculture. Table 3 and the previous estimates suggest that workers leaving agriculture tend to be the more educated ones or those with higher wages. The estimated changes in Table 3 highlight the importance of treating labor as a differentiated input.

Table 3 shows important temporal differences in the rate of change of the labor input. In particular, the labor input's rate of

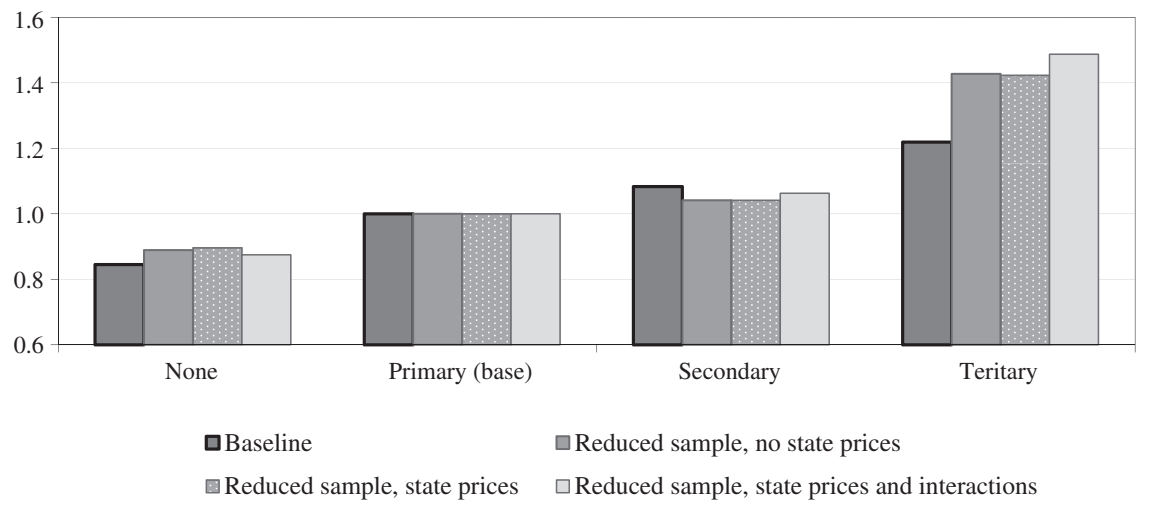

Fig. 2. Agricultural log-wage by education group with and without state controlled prices. 
Table 3

Average annual growth rate of Chinese agricultural labor input and labor quality.

\begin{tabular}{|c|c|c|c|c|c|c|c|c|c|c|}
\hline & \multicolumn{8}{|c|}{ Estimates based on Table 2} & \multirow{2}{*}{\multicolumn{2}{|c|}{$\begin{array}{l}\text { "Shadow wage" } \\
\text { estimates }\end{array}$}} \\
\hline & \multicolumn{2}{|l|}{ (1) } & \multicolumn{2}{|l|}{$(2)$} & \multicolumn{2}{|l|}{ (3) } & \multicolumn{2}{|l|}{ (4) } & & \\
\hline & $\Delta \ln L$ & $\Delta \ln Q$ & $\Delta \ln L$ & $\Delta \ln Q$ & $\Delta \ln L$ & $\Delta \ln Q$ & $\Delta \ln L$ & $\Delta \ln Q$ & $\Delta \ln L$ & $\Delta \ln Q$ \\
\hline 1991-1993 & -2.73 & 1.92 & -5.88 & -1.22 & -3.68 & 1.02 & -2.10 & 2.55 & & \\
\hline 1993-1997 & -4.40 & 0.64 & -5.31 & -0.26 & -4.50 & 0.51 & -3.79 & 1.24 & -5.94 & -1.75 \\
\hline 1997-2000 & -2.05 & 0.36 & -2.98 & -0.55 & -1.74 & 1.26 & -1.90 & 0.25 & -4.27 & -3.45 \\
\hline 2000-2004 & -4.76 & -0.76 & -4.85 & -0.85 & -5.45 & 1.61 & -4.52 & -0.44 & -4.76 & -1.73 \\
\hline 2004-2006 & -7.69 & 0.69 & -7.82 & -0.05 & -8.31 & 0.01 & -7.86 & -0.37 & -7.87 & -1.50 \\
\hline 2006-2009 & -7.73 & -0.08 & -7.83 & -0.17 & -8.03 & 0.26 & -7.62 & -0.03 & -7.01 & -0.51 \\
\hline 1991-2009 & -4.82 & 0.24 & -5.58 & -0.51 & -5.17 & 0.03 & -4.54 & 0.46 & -5.13 & -1.60 \\
\hline
\end{tabular}

Note. - Estimates of changes in the labor input are based on a Divisia index of labor input. The "shadow wage" approach is discussed in Appendix A.

decline has accelerated in recent years. In terms of regional differences, specifications (3) and (4) in Table 3 apply the set of coefficients for coastal and inland provinces to the national distribution of labor, and compute the growth rates of the labor input and labor quality. Using the coastal coefficients, the agricultural labor input decreased at $5.17 \%$ per year. Using the inland coefficients, we get a decrease of $4.54 \%$ per year. As argued above, the difference between these estimates of the labor input may in part be due to geographic or legal barriers to labor mobility.

There are three important observations regarding specifications (3) and (4) in Table 3. First, the labor input declined at faster rates according to the coastal coefficients; the difference between the coastal and inland estimates is $0.63 \%$. This positive difference is consistent with the idea that coastal areas face fewer mobility barriers than inland areas. Second, labor quality increased at smaller rates in coastal areas, perhaps due to the selective migration of agricultural workers in these areas. In our sample, the quality of the labor input shows the fastest increase in the rural inland areas. Third, even if one considers the coefficients for inland areas, the labor input declined at rates exceeding $4.5 \%$ per year. As we show immediately below, the difference between the labor input measured according to the coastal coefficients and that measured according to the inland coefficients produces small differences in agricultural TFP.

Finally, notice that the estimates of the labor input based on the "shadow wage" approach, suggest a decline in the labor input in agriculture of about $5 \%$. This estimate lies between our estimates based on the other specifications in Table 3.

\subsection{Total factor productivity growth}

In addition to the labor input, in order to estimate TFP growth, we need aggregate measures of agricultural output, capital, and land. Data is mostly taken from the China Statistical Yearbook (Various years) with necessary adjustments. First, according to Young (2003), the official GDP deflator underestimates inflation. Young (2003) suggests using alternative official price indices to construct real GDP series. We follow Young's approach and deflate the nominal GDP in agriculture, industry, and services by the purchasing price index for farm products, the ex-factory price index for industrial products, and the consumer price index (for services), respectively. This data shows that agricultural output grew at 5.6\% on average from 1978 to 2009.

Second, because the CSY only contains one measure of the national capital stock and does not break down capital into different categories by sectors, our measurement of the agricultural capital stock relies on the estimates made by Dekle and Vandenbroucke (2010, 2012). They aggregate provincial data, which does decompose capital into three sectors, into a national measure. In their data, the growth rate of capital in agriculture is $3.1 \%$ annually. Third, labor is measured by the number of persons who engaged in working activities and received some income during each calendar year. The employment data from the CSY shows that after 1978, the number of people engaged in agriculture increased by about $1.1 \%$ annually, which is much less than Young's (2003) estimates for the whole country (2.2\%) and for the industrial sector (4.5\%). Last, land in the agricultural sector is measured by the total area sown with crops. This figure does not vary much over time; its annual growth rate is $0.3 \%$.

\subsubsection{Factor shares}

The share of labor income is typically obtained either from national accounts or input-output tables. Using data from the Chinese input-output tables in 1992, 1995, 1997, and 2000, the ratios of compensation for laborers in agricultural value added are $0.84,0.84,0.88$, and 0.88 , respectively. Not only are those numbers substantially higher than Young's (2003) estimates for the non-agriculture sector, they are much higher than the shares found in other East Asian countries. ${ }^{22}$ This abnormally high share of labor appears to be due to the fact that labor compensation in the agricultural sector is calculated by adding the "net incomes" of various activities associated with production in the rural area; see OECD (2000). ${ }^{23}$ In other words, the measure from the input-output tables appears to contain not only "labor income," but a combination of many other incomes. Since there is no market for land, we must find ways to obtain a separate valuation of land relative to capital and labor.

We first estimate factor shares using an aggregate Cobb-Douglas production function. This approach is similar to that taken by Chow (1993), who argued that the capital, labor, and land shares are 0.25 , 0.40 and 0.35 , respectively, for Chinese agriculture for the period 1952-1980. We next extend Chow's (1993) study to 2003 for comparability. The aggregate agricultural production function is specified by:

$\ln Y=\alpha_{0}+\alpha_{K} \ln K+\alpha_{T} \ln T+\alpha_{L} \ln L+\alpha_{t} t$,

or by the constant returns to scale assumption:

$\ln (Y / L)=\alpha_{0}+\alpha_{K} \ln (K / L)+\alpha_{T} \ln (T / L)+\alpha_{t} t$,

where $Y$ is output, $K$ is capital, $T$ is land, and $L$ is labor. We exclude the years 1958 through 1969. As Chow (1993) suggests, these years are irregular due to political movements such as the Great Leap Forward

\footnotetext{
22 Hayami et al. (1979) report that agricultural labor shares in Japan, Taiwan, Korea, and the Philippines range from 0.31 to 0.53 over the period starting with the beginning of the twentieth century and ending with the nineteen-sixties. Data from input-output tables in China fall outside of this range by a wide margin. Our estimated labor share in agriculture for China is 0.38 , which falls within the previous range.

${ }^{23}$ In particular, employee compensation in the agricultural sector is calculated as the net incomes per capita in rural areas times the population in rural areas, whereas for all other industries, the employee compensation equals average wages times the number of workers. Fan and Zhang (2002) measure the share of labor cost in total agricultural production in China in 1997 as roughly $\alpha_{L}=30 \%$. The labor cost is based on survey data on daily wages and the number of working days. Their estimate is consistent with ours, although their estimation method differs considerably from ours.
} 
Table 4

Estimates of the agricultural production function.

\begin{tabular}{|c|c|c|c|c|c|c|}
\hline \multicolumn{3}{|c|}{ Dependent variable: $\ln Y$} & \multicolumn{2}{|c|}{$\begin{array}{l}\text { Dependent } \\
\text { variable: } \ln (Y / L)\end{array}$} & \multirow[t]{2}{*}{$\begin{array}{l}\text { Time trend } \\
\text { after } 1978\end{array}$} & \multirow[t]{2}{*}{$R^{2}$} \\
\hline $\ln K$ & $\ln L$ & $\ln T$ & $\ln (K / L)$ & $\ln (T / L)$ & & \\
\hline \multicolumn{7}{|c|}{ Period: 1952-1980. Based on Chow (1993) } \\
\hline $\begin{array}{l}0.25 \\
(0.044)\end{array}$ & $\begin{array}{c}0.32 \\
(0.095)\end{array}$ & $\begin{array}{l}1.034 \\
(0.024)\end{array}$ & & & & 0.98 \\
\hline \multicolumn{7}{|c|}{ Period: 1952-2003 } \\
\hline $\begin{array}{l}0.26 \\
(0.082)\end{array}$ & $\begin{array}{c}0.39 \\
(0.15)\end{array}$ & $\begin{array}{c}0.68 \\
(0.46)\end{array}$ & & & $\begin{array}{c}0.039 \\
(0.003)\end{array}$ & 0.99 \\
\hline & & & $\begin{array}{c}0.25 \\
(0.081)\end{array}$ & $\begin{array}{l}0.37 \\
(0.081)\end{array}$ & $\begin{array}{c}0.041 \\
(0.003)\end{array}$ & 0.97 \\
\hline
\end{tabular}

Note. - Standard errors in parentheses. The period from 1958 to 1969 is excluded from the estimations. For the period 1952-2003, we rely on an extension based on the investment data of Chow (1993).

and the Cultural Revolution. The CSY contains data for output, labor, and land before 1978. For capital, the CSY does not break down capital into different sectors, so we rely on the investment data estimated by Chow (1993). We set the initial capital at 1952, such that our constructed capital series matches the data in 1978 .

The coefficients of the variable inputs represent the factor shares in production. The variable $t$ has a value of zero from 1952 until 1977, and increases by one thereafter. Thus, the coefficient for $t$ can be read as a crude estimate of total factor productivity growth in the Chinese agricultural sector after 1978. Table 4 shows the regression results. The coefficients for labor and capital from both regressions are almost identical. The estimates indicate that the factor share of land and capital are about $37 \%$ and 25\%, respectively. The labor share is 38\%. These values are consistent with Chow's (1993) estimates. The sum of land and labor shares is $75 \%$, which is close to the "labor income" reported in the input-output tables. This suggests that the input-output tables appear to report a composite of labor and land returns. The two regressions also suggest that there was a $4 \%$ increase in productivity in the Chinese agricultural sector for the period 1978-2003. This number is lower than our TFP estimate based on microdata, reported immediately below. The reason is that the estimates in Table 4 do not disaggregate the labor input in order to take into account quality differences.

An alternate way of obtaining factor shares is to use our microestimates of the agricultural production function. In Appendix A we use these estimates to determine the labor and land shares, as well as to estimate TFP growth rates based on a time trend, as in Table 4. The estimates are not directly comparable, because we do not include capital in these estimates (because capital is not available in the survey data). We also use household data and hours worked (not the number of workers) to measure the labor input. Nonetheless, the estimated land share, $34 \%$, is virtually the same as in Table 4. The estimated labor share is $23 \%$. We can also estimate TFP growth using a time trend in the production function. Our time trend estimate for the years 1991 through 2009 is 6.5\%. This estimate is virtually the same as our estimate of TFP growth, presented immediately below, and is greater than the trends in Table 4, which, as we just mentioned, do not take into account quality differences in the labor input.

\subsubsection{Overview}

TFP growth can be estimated as follows:

TFP growth $=\frac{d \ln Y}{d t}-\alpha_{K} \frac{d \ln K}{d t}-\alpha_{L} \frac{d \ln L}{d t}-\alpha_{T} \frac{d \ln T}{d t}$,

where $\alpha_{K}=25 \%$ is the capital share, $\alpha_{L}=38 \%$ is the labor share, and $\alpha_{T}=37 \%$ is the land share. These factor shares are suggested by the aggregate agricultural production function from Table 4 , and by our estimates of the aggregate production function based on microdata. Official data (CSY) for the Chinese economy for the years 1978 through 2009 shows that agricultural output grew annually at $5.6 \%$, capital grew annually at $3.1 \%$, and land barely changed, only increasing by $0.3 \%$ annually. We also show that the labor input decreased at an average annual rate of $4.5-5.5 \%$. Therefore, agricultural TFP growth in China between 1991 and 2009 in Eq. (21) increased at an annual rate of $6.5 \%{ }^{24}$ Since there is no farm-level data for the early part of the reform period, we use this estimate for the entire period in the subsequent counterfactual analysis.

\section{Quantitative results}

In this section, we use our theoretical model and our previous measurement results to examine the contribution of agricultural productivity to China's post-reform growth and sectoral reallocation.

\subsection{Baseline calibration}

The baseline calibration relies on our measurement results for agriculture, and on Young's (2003) results for non-agriculture. Since technological change is labor-augmenting, productivity growth in each sector is $\mu_{a}=6.5 \% \times\left(1-\alpha_{a}\right)$ and $\mu_{m}=1.4 \% \times\left(1-\alpha_{m}\right)$. We use our estimate of the capital share in agriculture, $\alpha_{a}=25 \%$. In our baseline calibration, we use Young's (2003, p. 1255) non-agricultural capital share, $\alpha_{m}=54 \%$. The parameter $\alpha_{m}$ plays a central role in this transition, and we present alternate values of $\alpha_{m}$ later on.

A period is one year. The initial period is 1978 and we consider a transition of 30 years. Population growth is $v=1 \%$, the depreciation rate is $\delta=5 \%$, and the discount rate is $\rho=3 \%$. The steady state expenditure share of agricultural goods is set at $\omega=0.15$. We normalize $A_{a}(0)=1$. We calibrate $\gamma$ to match the level of the employment share in agriculture in the Chinese economy in 1978; that is, $n_{a}(0)=70 \% .{ }^{25}$ We calibrate $\hat{k}_{m}^{*} / \hat{k}_{m}(0)$ to match an average growth rate of income per worker of $5.5 \%{ }^{26}$ Aggregate output growth per worker between 1978 and 1998 in China was 5.2\%, according to Young (2003, p. 1258). Dekle and Vandenbroucke's (2010) estimates suggest a 5.5\% growth rate between 1978 and 2008. Table 5 summarizes the values of the parameters.

Figs. 3 and 4 provide information about the employment and output shares in the data and simulations. Fig. 3 displays the employment share based on official data, and the estimate from Brandt et al. (2008). ${ }^{27}$ Table 6 provides additional information about the average growth rate in the aggregate and in the non-agricultural sector, growth in the output-capital ratio, the rate of return to capital, and the relative price of agricultural goods. We take the rate of return to

\footnotetext{
24 Based on a range of 4.5 to $5.5 \%$ decline in the labor input, the range of TFP growth is $6.4 \%$ to $6.8 \%$. The labor share from the input-output data, 0.84 , suggests a much higher TFP growth rate. If we use $\alpha_{L}=84 \%, \alpha_{T}=0 \%$, and $\alpha_{K}=25 \%$, our estimate of TFP would exceed $8 \%$ per year. Brandt et al. (2008, p. 723) suggested a labor share of $\alpha_{L}=50 \%$. If we use that value in Eq. (21), TFP would be $7.1 \%$. Fan and Zhang (2002) argued that the official data overstated the TFP growth by about $2 \%$. Their estimate of agricultural TFP growth from 1979 till 1997 is about 3.3\% per year. Their measures of labor input, however, are homogenous, and ignore changes in the composition of China's agricultural labor. This implies that part of the improvements in labor quality and the reduction in agricultural labor input might be allocated to TFP growth. 25 CSY reports "Engel's coefficients" for urban and rural households. These coefficients measure the proportion of income spent on food. In Table 6, the share of total expenditures on agricultural goods, $\psi_{a}(t)$, reports the national figures from the CSY. ${ }^{26}$ In the baseline calibration, the steady-state value of normalized capital in Eq. (16) is $\hat{k}_{m}^{*}=35.9$, and the fraction of labor allocated to agriculture in Eq. (17) is $n_{a}^{*}=14.6 \%$. In order to obtain a high transitional growth rate of output, initial capital is $\hat{k}_{m}(0)=5.3$. 27 Brandt et al. (2008) conclude that the official Chinese data may underestimate agricultural employment, due to the exclusion of private employment prior to 1984; the incomplete tabulation of self-employed individuals, who receive income outside of agriculture; and the erroneous inclusion of migrants. Their alternative series of agricultural employment in Fig. 3 is based on information from the Chinese census and rural household surveys.
} 
Table 5

Parameter values.

\begin{tabular}{|c|c|c|c|}
\hline \multicolumn{2}{|c|}{ Parameter description } & \multirow{2}{*}{$\begin{array}{l}\text { Baseline } \\
\text { value }\end{array}$} & \multirow{2}{*}{$\begin{array}{l}\text { Alternate } \\
\text { value }\end{array}$} \\
\hline A. Preferences & & & \\
\hline$\omega$ & $\begin{array}{l}\text { Expenditure share of agricultural } \\
\text { consumption }\end{array}$ & 0.15 & - \\
\hline$\gamma$ & $\begin{array}{l}\text { "Subsistence level" of agricultural } \\
\text { consumption }\end{array}$ & 0.65 & 1.73 \\
\hline$\rho$ & Time discount rate & 0.03 & - \\
\hline$v$ & Population growth rate & 0.01 & - \\
\hline \multicolumn{4}{|l|}{ B. Technology } \\
\hline$\alpha_{a}$ & Capital share in agriculture & 0.25 & - \\
\hline$\alpha_{m}$ & Capital share in non-agriculture & 0.54 & 0.75 \\
\hline$\delta$ & Depreciation rate & 0.05 & - \\
\hline \multicolumn{4}{|c|}{ C. Productivity and initial conditions } \\
\hline$\mu_{a} /\left(1-\alpha_{a}\right)$ & Productivity growth in agriculture & 0.065 & - \\
\hline$\mu_{m} /\left(1-\alpha_{m}\right)$ & Productivity growth in non-agriculture & 0.014 & - \\
\hline$A_{a}(0)$ & Initial productivity in agriculture & 1 & - \\
\hline$\hat{k}_{m}^{*} / \hat{k}_{m}(0)$ & Initial normalized capital in non-agriculture & 6.70 & 4.26 \\
\hline
\end{tabular}

Note. - The parameters are described in the text.

capital from Bai et al. (2006). They measure $r$ as the ratio of the capital share in output to the capital-output ratio (net of depreciation). From 1978 to 2005, their rate of return to capital in China is about 23\%, which is driven by a relatively low capital-output ratio (1.5), and by a relatively high capital share (49\%).

Finally, the price data are based on the general price index of farm products and the ex-factory price indices of industrial products taken from various issues of CSY. We report the change in relative prices over the 30 years of our simulations, though we should acknowledge that the price data is subject to a number of caveats that make a definite interpretation difficult. ${ }^{28}$

The baseline model reproduces well structural changes. Fig. 3 shows that the share of agricultural employment in the model starts at about $70 \%$, and gradually decreases over 30 years to $22 \%$, matching the historical data. The baseline calibration yields employment shares closer to those estimated by Brandt et al. (2008), especially at the beginning of the reform period. The baseline model also yields a decline in the output share in agriculture. The model, however, does not fit the initial level of the output share. The model's output share of agriculture starts at around 58\%. In the data, agriculture accounted for about $30 \%$ of GDP in 1978, and about $11 \%$ of GDP in 2008; see Fig. 4. The baseline calibration also predicts rapid convergence, capital-deepening, rapid growth in non-agriculture, and a rapid decline in relative prices and the rate of return to capital. In the data, output per worker in the non-agricultural sector grew at slower rates than in the aggregate; the output-capital ratio remained virtually unchanged between 1978 and 1998; see, e.g., Young (2003, p. 1259 ), and the rate of return to capital was stable during the 1980s and 1990s; see, e.g., Bai et al. (2006) and Song et al. (2011).

We can directly decompose the overall growth rate into the fractions due to agriculture, non-agriculture, and sectoral reallocation. In the data, agricultural output grows at $4.5 \%$ per year, and the initial output share of agriculture is $30 \%$. The contribution of agriculture to total output is therefore $4.5 \% \times 0.3=1.35 \%$. Similarly, non-agricultural growth

\footnotetext{
${ }^{28}$ Before 1984, the prices of important materials were set by the government and remained unchanged for a long time. During the initial part of the reform period, artificially low food prices, along with other consumer goods prices, began to increase; see Lin and Yu (2009). This initial increase in prices likely reflects the fact that prices were below their equilibrium value. How distorted were relative prices initially? Lardy (1983, Chapter 3) shows that in 1976, the price of fertilizers relative to rice in China was more than twice as high as the same relative price in other Asian countries. He also shows that in 1980, the quota prices for rice, wheat, and corn were about half the average prices found in rural markets. Both these figures suggest that, before the reform, the Chinese government artificially suppressed the agricultural price level by about $50 \%$.
}

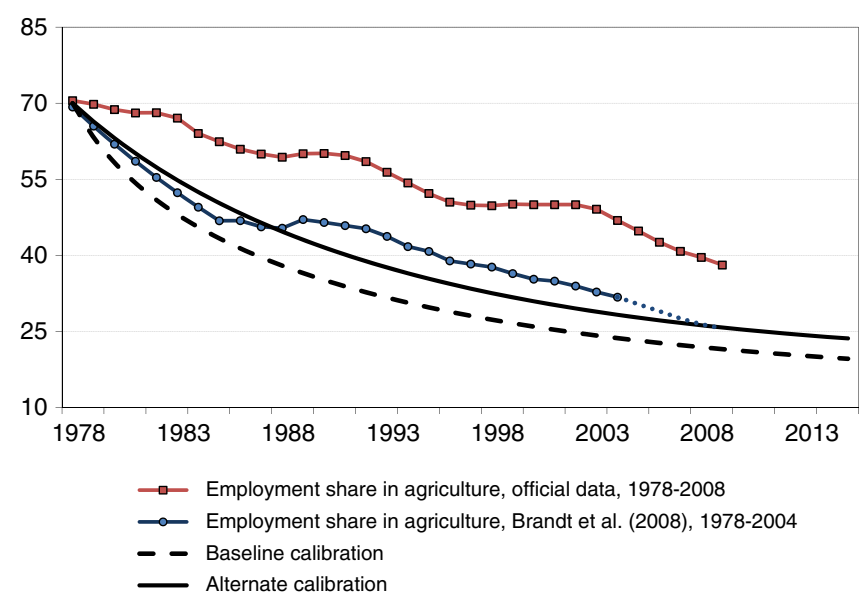

Fig. 3. Employment share in agriculture: Data and model, 1978-2008.

is $3.3 \%$, so its contribution is $3.3 \% \times 0.7=2.31 \%$. The contribution of sectoral reallocation is $5.5 \%-1.35 \%-2.31 \%=1.84 \%$, which is more than one-third of the total growth. Our baseline calibration yields an agricultural contribution of $0.64 \% \times 0.58=0.37 \%$, a non-agricultural contribution of $8.3 \% \times 0.42=3.49 \%$, and a sectoral reallocation contribution of $5.5 \%-0.37 \%-3.49 \%=1.67 \%$. The role of the sectoral reallocation is similar to what we observe in the data even though the model underestimates the impact from agriculture.

\subsection{Alternate calibration}

The baseline calibration has some counterfactual implications because the capital share in manufacturing is relatively low. A low value of $\alpha_{m}$ implies rapid convergence; see, e.g., Barro and Sala-i-Martin (1995). In King and Rebelo (1993, p. 921), for example, transitions that maintain high rates of return to capital require a capital share of the order of 0.9 .

There are several ways to motivate a higher capital share. Alternative interpretations that lead to the same value of the capital share will have the same implications for reallocations between agriculture and non-agriculture, which is the focus of our paper. The model considers a single form of capital. Using a broader concept of capital, such as human capital in Barro and Sala-i-Martin (1995), or intangible capital in Parente and Prescott (2000, chapter 5) increases the capital share. For instance, let $z_{m}$ denote the additional capital per worker, and let the augmented production function in the non-agricultural sector be $A_{m}\left[k_{m}\right]^{\alpha_{m}} z_{m}^{\theta} n_{m}$. (In our benchmark model, $\theta=0$.) The equality between the marginal products of capital implies that $\alpha_{m} z_{m}=\theta k_{m}$. The production function becomes $A_{m}\left[k_{m}\right]^{\alpha_{m}} z_{m}^{\theta} n_{m}=A_{m}^{\prime}\left[k_{m}\right]^{\alpha_{m}+\theta} n_{m}$, where $A_{m}^{\prime}=$ $A_{m} \theta / \alpha_{m}$, and the relevant capital share is $\alpha_{m}+\theta$, which exceeds $\alpha_{m}{ }^{29}$

The model also abstracts from reallocations within manufacturing. Song et al. (2011) constructed a microfounded model of the Chinese economy with an emphasis on resource reallocations within manufacturing. In their model, "during the transition, the dynamic equilibrium has AK features: within each type of firm, the rate of return to capital is constant"; see Song et al. (2011, p. 204). In an AK technology for the non-agricultural sector, the marginal product of capital is constant and the capital share tends to one; $\alpha_{m} \rightarrow 1$.

We cannot use an AK technology since the sectoral reallocation would go away entirely; see, e.g., (10). For the alternate calibration, we set $\alpha_{m}=0.75$. All other parameter values remain the same as

29 Barro and Sala-i-Martin (1995, Fig. 2.5) showed that the transitional properties of the neoclassical model improve considerably when using higher values for $\alpha_{m}$. Using relatively higher capital shares, Parente and Prescott (2000, p. 80) showed that the neoclassical growth model "with intangible capital [...] matches the development miracle of Japan." 


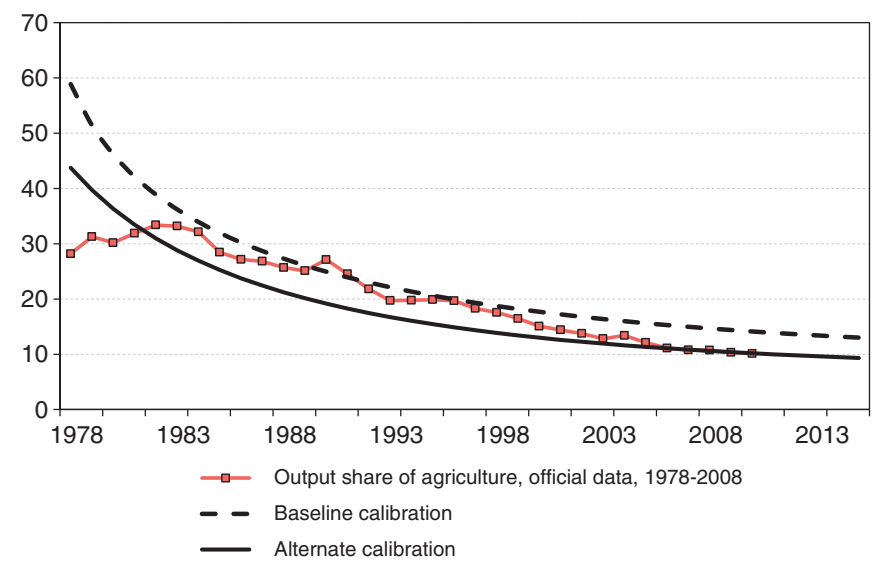

Fig. 4. Output share in agriculture: Data and model, 1978-2008.

in Table 5, but we recalibrate $\gamma$ and $\hat{k}_{m}^{*} / \hat{k}_{m}(0)$, so as to obtain $n_{a}(0)=$ $70 \%$ and a 5.5\% growth rate of GDP per worker during the transition. The alternate value of $\alpha_{m}$ better fits the transitional path of the employment and output shares, and yields slower convergence and more stable rates of return to capital and output-capital ratios. This alternate parameterization still predicts a high growth rate of output in the non-agricultural sector and capital-deepening. Later on, we consider a scenario where the capital share is even higher, $\alpha_{m}=0.85$. This value makes the dynamics in the non-agricultural sector even closer to the AK model.

\subsection{Counterfactual experiments}

The transitional path of our model economy depends on the productivity growth in the agricultural and non-agricultural sectors. We measure the contribution of agricultural TFP to China's structural change and post-reform growth by solving the model when each of these TFP growth rates is equal to zero. We perform these experiments for both calibrations.

Table 6 presents our results. Let us first consider Panel A. The model attributes the majority of the sectoral reallocation of employment, output, and consumption to agricultural TFP. For example, if $\mu_{a}=0$, the employment share only declines by one-third of the total predicted decline. In contrast, the reallocation of employment, output, and consumption remain virtually unchanged if $\mu_{m}=0$. Let us next consider Panel $\mathrm{B}$. The baseline calibration predicts modest growth effects. If $\mu_{a}=0$, the average growth rate declines to $5.0 \%$. If $\mu_{m}=0$, the average growth rate declines to $4.5 \%$. In the alternate calibration, setting $\mu_{a}=0$ lowers aggregate growth to $4.4 \%$. We find then that the growth effects of agricultural TFP are as large as the growth effects of non-agricultural TFP.

The growth effects of TFP are modest due to the fact that a high fraction of aggregate growth is catch-up growth. In the alternate calibration, initial capital is higher than in the baseline case and the growth effects of agricultural TFP are greater. (Large capital shares, e.g., $\alpha_{m}=0.85$, yield even larger growth effects for agricultural TFP; see Table 7.) Agricultural TFP, however, has greater effects on the non-agricultural sector's growth rate. In the baseline case, setting $\mu_{a}=0$ lowers average growth, $\overline{\mathrm{g}}_{m}$, from $8.3 \%$ to $6.7 \%$. Under $\mu_{m}=0$, $\overline{\mathrm{g}}_{m}$ declines to $7.3 \%$. In the alternate calibration, the contribution of $\mu_{a}$ to $\bar{g}_{m}$ is also larger than that of $\mu_{m}$. We find that agricultural TFP is more important for non-agricultural growth than non-agricultural TFP.

The model predicts a decline in the output-capital ratio due to capital deepening. The data, as pointed out by Young (2003, p. 1258), suggests that there is no capital deepening in non-agriculture. If $\mu_{a}=0$, the model predicts a slower capital accumulation and a smaller increase in capital relative to output.
Let us finally consider Panel $\mathrm{C}$. The model predicts a decline in the rate of return to capital as well as a decline in the relative price of agricultural goods. The changes in $r(t)$ are more or less independent of agricultural and non-agricultural TFP. These changes are driven almost exclusively by capital accumulation. The rates of return for the baseline calibration are higher than in the alternate calibration because the initial capital is lower. Prices $p(t)$ are driven primarily by agricultural TFP. If $\mu_{a}=0$, the model predicts an increase rather than a decrease in relative prices. This finding highlights the importance of price changes for the sectoral reallocations described in Panel A.

Agricultural TFP plays a central role in sectoral reallocations. One channel for these reallocations is a decline in relative prices. Evidence in support of this channel is difficult to ascertain due to the initial price distortions in China (Footnote 28). Relative agricultural prices have declined steadily since the mid-1980s, when agricultural reforms began to accelerate; see, e.g., Brandt et al. (2008, Figure 17B4) and Dekle and Vandenbroucke $(2010,2012)$. Finally, notice that the growth effects of agricultural TFP are greater than the growth effects of non-agricultural TFP for the alternate calibration. Agricultural TFP is especially important for growth in the non-agricultural sector. Capital accumulation, even under the alternate parameter values, still yields high catch-up growth, capital-deepening, and a decline in the rates of return to capital.

\subsection{Alternative experiments}

In this section, we measure the importance of labor mobility, and consider scenarios featuring higher productivity growth in the non-agricultural sector, as well as market distortions. ${ }^{30}$ We also consider an even higher capital share in non-agriculture.

\subsubsection{No labor mobility}

Table 7 measures the effect of labor mobility on aggregate and non-agricultural growth. The assumption is that there are no reallocations in employment and output: $n_{a}(t)=n_{a}(0)=70 \%$. In the absence of labor mobility, aggregate growth is $4.6 \%$, which also equals the growth rate in the non-agricultural sector. The growth effect of labor mobility is large, particularly in the non-agricultural sector, whose baseline growth is $\overline{\mathrm{g}}_{m}=8.3 \%$. Using the alternate parameter values yields even stronger effects. We do not display these results to save space. The growth rates become $\overline{\mathrm{g}}=\overline{\mathrm{g}}_{m}=3.9 \%$. Overall, labor reallocations account for about one-third of aggregate growth, and about half of non-agricultural growth during the transition.

\subsubsection{Higher TFP in non-agriculture}

So far, we have used a moderate TFP growth rate for the non-agricultural sector. Using official data, the growth in TFP in the non-agricultural sector between 1978 and 1998 was 3.0\%; see Young (2003, Table 24). Brandt and Zhu (2010) estimate the (non-state) non-agricultural TFP growth rate to be $4.56 \%$ per year from 1978 to 2007. ${ }^{31}$ Table 7 replaces our benchmark value of $\mu_{m} /\left(1-\alpha_{m}\right)=1.4 \%$ by $3.0 \%$ and $4.56 \%$. There are only minor differences in terms of sectoral reallocations. The higher TFP in the non-agricultural sector, however, increases aggregate growth to $7 \%$ and $8 \%$, and growth in the non-agricultural sector to $9 \%$ and $11 \%$. As Brandt et al. (2008) argued,

\footnotetext{
${ }^{30}$ In our theory section we noted that the importance of $\gamma$ declines over time. We solved the model under $\gamma=0$ in order to verify that this allocation coincides with our asymptotic results under $\gamma>0$. These results are available upon request.

31 Brandt and Zhu (2010) also estimate the growth of agricultural TFP to be $6.20 \%$ between 1978 to 2007. Their estimate, however, does not account for labor quality differences. Overall, our alternate measures of non-agricultural TFP are more conservative than some existing estimates. Brandt et al. (2012), for example, present a firm-level study of Chinese manufacturing TFP. In their estimates, manufacturing TFP grew by $8 \%$ annually during the period from 1998 until 2006. They found that net entry contributes by about half of this growth. They also found that the reallocations toward more productive firms had small effects.
} 
Table 6

Simulation results and counterfactuals.

\begin{tabular}{|c|c|c|c|c|c|c|c|}
\hline & \multirow[t]{2}{*}{ Data } & \multirow[t]{2}{*}{ Baseline calibration } & \multicolumn{2}{|c|}{ Counterfactuals } & \multirow[t]{2}{*}{ Alternate calibration } & \multicolumn{2}{|c|}{ Counterfactuals } \\
\hline & & & $\mu_{a}=0$ & $\mu_{m}=0$ & & $\mu_{a}=0$ & $\mu_{m}=0$ \\
\hline \multicolumn{8}{|c|}{ A. Sectoral allocations of labor, output, and consumption } \\
\hline$n_{a}(0)$ & 0.70 & 0.70 & 0.70 & 0.70 & 0.70 & 0.70 & 0.70 \\
\hline$n_{a}(30)$ & $0.25-0.35$ & 0.22 & 0.48 & 0.22 & 0.27 & 0.59 & 0.27 \\
\hline$\theta_{a}(0)$ & 0.30 & 0.58 & 0.58 & 0.58 & 0.44 & 0.44 & 0.44 \\
\hline$\theta_{a}(30)$ & 0.11 & 0.15 & 0.36 & 0.15 & 0.11 & 0.32 & 0.11 \\
\hline$\psi_{a}(0)$ & 0.58 & 0.53 & 0.53 & 0.52 & 0.55 & 0.55 & 0.72 \\
\hline$\psi_{a}(30)$ & 0.39 & 0.22 & 0.38 & 0.22 & 0.22 & 0.39 & 0.23 \\
\hline \multicolumn{8}{|c|}{ B. Average growth rates } \\
\hline$\overline{\mathrm{g}}$ & 0.055 & 0.055 & 0.050 & 0.045 & 0.055 & 0.044 & 0.051 \\
\hline$\overline{\mathrm{g}}_{m}$ & 0.036 & 0.083 & 0.067 & 0.073 & 0.072 & 0.051 & 0.068 \\
\hline$\overline{\mathrm{g}}_{y / k}$ & 0.004 & -0.035 & -0.031 & -0.039 & -0.017 & -0.012 & -0.020 \\
\hline \multicolumn{8}{|c|}{ C. Rate of return to capital and relative prices } \\
\hline$r(0)$ & 0.23 & 0.25 & 0.25 & 0.25 & 0.15 & 0.15 & 0.15 \\
\hline$r(30)$ & 0.21 & 0.11 & 0.11 & 0.10 & 0.12 & 0.12 & 0.11 \\
\hline$p(30) / p(0)$ & 1.07 & 0.54 & 2.22 & 0.42 & 0.54 & 2.21 & 0.48 \\
\hline
\end{tabular}

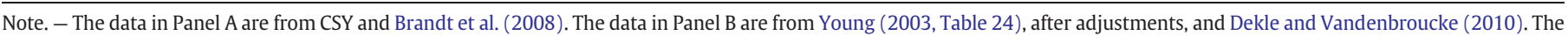
rates of return in Panel C are taken from Bai et al. (2006). Price data are from CSY.

a higher TFP growth rate in the non-agricultural sector yields a slower decline in the rate of return to capital and an increase in agricultural prices. When $\mu_{m} /\left(1-\alpha_{m}\right)=3.0 \%$ or $4.56 \%$, prices decrease at a slower rate compared to the baseline case.

\subsubsection{Labor market distortions}

Table 7 examines the role of labor distortions, $\tau_{n}^{i}$. We consider $1+\tau_{n}^{m}=50 \%$ and $\tau_{n}^{a}=0$; these values bias capital toward the non-agricultural sector; see, e.g., Eq. (10). An important effect of $\tau_{n}^{m}$ is to lower the output share in agriculture. In the baseline specification in Table $6, \theta_{a}(0)=58 \%$; now, $\theta_{a}(0)=46 \%$. Thus, the relatively low value of the output share in agriculture in China in 1978 may be partly due to the distortions during the pre-reform period. Biasing capital toward non-agriculture in the way specified here increases aggregate growth only marginally, to $5.6 \%$. This increase contrasts with a reduction in the growth rate of the non-agricultural sector. In our baseline parameterization, $\overline{\mathrm{g}}_{m}=8.6 \%$, whereas if we include labor distortions, $\overline{\mathrm{g}}_{m}=7.5 \%$. Non-agricultural growth declines as the diminishing returns to capital become more important for this sector. ${ }^{32}$

\subsubsection{Higher capital share}

Some of the model's capital implications are problematic, even with $\alpha_{m}=0.75$. Here we consider $\alpha_{m}=0.85$, and recalibrate $\gamma$ and $\hat{k}_{m}^{*} / \hat{k}_{m}(0)$ to obtain $n_{a}(0)=70 \%$ and $\bar{g}=5.5 \%$. In terms of sectoral allocations, the model performs the same as the baseline case in Table 6 . The initial output share $\theta_{a}(0)$, however, is lower. The growth rate in the non-agricultural sector is the lowest of all our exercises, there is virtually no capital deepening, and the rate of return to capital is constant. These aspects of the Chinese economy are not matched by the other parameterizations. Table 7 also examines the scenario where $\mu_{a}=0$. Here, the growth effects are considerably larger, and the aggregate growth rate declines to $3.7 \%$. Growth in the non-agricultural sector also declines to $3.9 \%$. Since capital is very productive with $\alpha_{m}=0.85$, a limited transfer of workers toward the non-agricultural sector becomes the main limitation preventing rapid economic growth.

\section{Conclusion}

The first contribution of this paper has been to use microeconomic farm data to measure the rate of growth of agricultural TFP in China,

\footnotetext{
32 We also examined price distortions, $\tau_{p}^{i}$. Their main effect is to lower the output share $\theta_{a}(0)$. Their growth implications are similar to those of labor distortions.
}

while recognizing the differentiation in the labor force's human capital. We found that the labor input declined at a 4.5-5.5\% annual rate, and that this decline was fairly robust across a number of specifications. We also found that between 1991 and 2009, agricultural TFP grew at an average annual rate of $6.5 \%$. This number is many times higher than the rate of growth of TFP in the non-agricultural sector estimated by Young (2003), even without correcting for measurement problems typical of official Chinese data. Our findings support the common belief that the agricultural sector accounts for a large fraction of the efficiency gains of the Chinese economic reform.

What role did agriculture play in China's overall economic growth and structural changes during the reform period? To quantitatively examine agriculture's role, we developed a two-sector neoclassical growth model with non-homothetic preferences, heterogeneous sectoral Cobb-Douglas production functions, and exogenous and heterogeneous productivity growth. The model takes into account many of the possible linkages between the agricultural and the non-agricultural sectors. The model also effectively reproduced the path of China's economy since 1978.

Within the context of the model, we performed a series of counterfactual exercises in order to measure the contribution of agricultural and non-agricultural TFP to sectoral and overall economic growth, and to structural changes. Agricultural productivity was the main factor in

Table 7

Alternative experiments.

\begin{tabular}{|c|c|c|c|c|c|c|}
\hline & \multicolumn{4}{|c|}{ Baseline calibration } & \multicolumn{2}{|c|}{ Alternative experiments } \\
\hline & \multicolumn{4}{|c|}{$\mu_{m} /\left(1-\alpha_{m}\right)$} & \multicolumn{2}{|l|}{$\alpha_{m}=0.85$} \\
\hline & $n_{a}=70 \%$ & $3.00 \%$ & $4.56 \%$ & $1+\tau_{n}^{a}=50 \%$ & $\begin{array}{l}\mu_{a} /\left(1-\alpha_{a}\right)= \\
6.5 \%\end{array}$ & $\mu_{a}=0$ \\
\hline \multicolumn{7}{|c|}{ A. Sectoral allocations of labor, output, and consumption } \\
\hline$n_{a}(0)$ & 0.70 & 0.70 & 0.70 & 0.70 & 0.70 & 0.70 \\
\hline$n_{a}(30)$ & 0.70 & 0.22 & 0.21 & 0.25 & 0.28 & 0.65 \\
\hline$\theta_{a}(0)$ & 0.58 & 0.58 & 0.58 & 0.46 & 0.31 & 0.31 \\
\hline$\theta_{a}(30)$ & 0.58 & 0.15 & 0.14 & 0.11 & 0.07 & 0.27 \\
\hline$\psi_{a}(0)$ & 0.53 & 0.53 & 0.53 & 0.40 & 0.69 & 0.69 \\
\hline$\psi_{a}(30)$ & 0.47 & 0.22 & 0.22 & 0.16 & 0.23 & 0.40 \\
\hline \multicolumn{7}{|c|}{ B. Average growth rates } \\
\hline$\overline{\mathrm{g}}$ & 0.046 & 0.067 & 0.079 & 0.056 & 0.055 & 0.037 \\
\hline$\overline{\mathrm{g}}_{m}$ & 0.046 & 0.095 & 0.108 & 0.075 & 0.066 & 0.039 \\
\hline$\overline{\mathrm{g}}_{y / k}$ & -0.025 & -0.032 & -0.029 & -0.030 & -0.010 & -0.004 \\
\hline \multicolumn{7}{|c|}{ C. Rate of return to capital and relative prices } \\
\hline$r(0)$ & 0.24 & 0.25 & 0.25 & 0.22 & 0.13 & 0.13 \\
\hline$r(30)$ & 0.11 & 0.13 & 0.14 & 0.11 & 0.11 & 0.11 \\
\hline$p(30) / p(0)$ & 0.54 & 0.71 & 0.94 & 0.50 & 0.50 & 2.07 \\
\hline
\end{tabular}


the reallocation of output and employment toward the non-agricultural sector. Agriculture also contributed to overall growth in similar amounts as non-agricultural TFP. The model also shows that agriculture's main contribution lies in reallocating workers to the non-agricultural sector. This reallocation of labor has been especially important in China because a considerable fraction of the labor force is still in agriculture, and because physical and human capital accumulation has proceeded at very rapid rates. These are precisely the kind of circumstances under which agriculture plays a fundamental role in economic development.

\section{Appendix A. TFP based on "shadow wages"}

In this Appendix, we estimate the labor input using a "shadow wage" approach. The shadow-wage approach assumes the existence of a household production function that has different types of labor as distinct inputs; that is, based on sex, age, and education; see, e.g., Jacoby (1993) and Skoufias (1994). The shadow wage of each farmer is simply the marginal product of labor, estimated using the agricultural production function.

The main goal of our additional specification is to control for endogeneity biases. For instance, the allocation of labor within a family is endogenously decided and is affected by unobservable factors (e.g., management skills, preference toward leisure, weather conditions, and so on). ${ }^{33}$ In the absence of appropriate econometric controls, however, estimates of marginal productivities are generally not very precise. We follow Levinsohn and Petrin (2003) and use the level of intermediate inputs as a control for this endogeneity problem. This approach yields consistent estimates of the marginal productivity of differentiated labor types that we use to measure productivity.

Assume a Cobb-Douglas production function:

$\ln Y=\sum_{i} \beta_{i} \ln L_{i}+\varepsilon$,

where $Y$ is the total value of output, $L_{i}$ is the various types of labor, and $\varepsilon$ is an error term. Based on the estimation result of Eq. (22), the shadow wage of labor type $i$ is:

$w_{i}=\hat{\beta}_{i} \frac{\hat{Y}}{L_{i}}$

where $\hat{\beta}_{i}$ is the estimated coefficient on $\ln L_{i}$. Under the Cobb-Douglas assumption, the marginal product of labor is proportional to the average product of labor, which we used in our benchmark calculations.

An OLS estimation of Eq. (22) suffers from an endogeneity problem. At least a part of the productivity is observed by the farmers only at a point in time early enough that it allows the farmer to change the labor input decision. If so, the error term in Eq. (22) is expected to influence the choice of inputs; it means that the regressors and the error term are correlated, which biases OLS estimates for Eq. (22). ${ }^{34}$

\footnotetext{
33 To sign the bias, one needs to know how the labor input relates to unobservables. For example, suppose women work in the farm only in good harvests, which implies that the share of female labor input increases within a season as the size of the output increases. In this case, female labor is positively correlated to the unobserved productivity shock, and OLS estimates of women's marginal productivity would tend to be biased upward (i.e., suggesting that they caused a high level of output), given that all other factors remain constant.

${ }^{34}$ This endogeneity problem in estimating a production function has a long history in economics. One approach is to use fixed-effects. But this fixed-effects estimator needs a strict exogeneity assumption of the inputs (Wooldridge, 2002), which implies that inputs cannot respond to productivity shocks. Instrumental variables estimation requires a proxy that correlates with the dependent variable, but uncorrelates with the error term. One candidate for such an instrument is the input price along with the assumption that there exists a competitive input market. However, input prices often do not have enough variation across households, and are not observed. Characteristics of a household, such as number of children, generally are not good for an instrument, since household composition reflects the life-long decision on how to allocate time and resources for a family.
}

Levinsohn and Petrin (2003) build upon Olley and Pakes (1996), who address the endogeneity problem by using investment as a proxy for unobserved productivity. Under certain assumptions, investment will be a monotone function of unobserved productivity and so inverting this function would yield consistent estimates of unobserved influences. Levinsohn and Petrin (2003) modify this approach by suggesting the intermediate input as a proxy instead of investment. Their motivation is that many firms report zero investment, but almost every firm uses a positive amount of intermediate inputs. For the same reason, we follow Levinsohn and Petrin (2003) by using land and intermediate inputs to proxy for the household-specific unobservable terms.

Following Olley and Pakes (1996) and Petrin et al. (2004), we use a third order polynomial function of land and intermediate inputs in the Cobb-Douglas production function (22). This method identifies the output elasticities of various types of labor which are our parameters of interest. Identifying the output elasticity of other factors is possible, but this requires further assumptions and procedures. These other elasticities, however, are not the main focus of our study. $^{35}$

We cross-classify the labor input into three factors: sex (s), age (a) and education (e). For age and education, we only consider three categories within each group. To obtain the marginal product of each type, we estimate the following production function:

$$
\ln Y_{t}=\beta_{0}+\sum_{l=1}^{18} \beta_{l} \ln L_{l t}+\sum_{i=0}^{3} \sum_{j=0}^{3-i} \delta_{i j} \ln M_{t}^{i} \ln T_{t}^{j}+\varepsilon_{t}
$$

where $Y_{t}$ is a household's total output at time $t, L_{l t}$ is the number of hours of work at time $t$ for labor type $l, M_{t}$ is the total expenditure of intermediate inputs, and $T_{t}$ is the land input. Based on the estimates on the labor input, $\hat{\beta}_{l}$, the marginal productivity (or shadow wage) of each individual from the sample was derived using Eq. (23). Table A1 reports estimates of $\beta_{l}$, and Table A2 reports the change in the agricultural labor input based the shadow wage estimates. These changes were also reported in Table 3.

Table A1

Estimates of agricultural production function.

\begin{tabular}{|c|c|c|c|c|c|c|}
\hline & \multicolumn{2}{|c|}{0 yrs education } & \multicolumn{2}{|c|}{ 1-6 yrs education } & \multicolumn{2}{|c|}{6 yrs education } \\
\hline & Male & Female & Male & Female & Male & Female \\
\hline$<25$ yrs old & $\begin{array}{c}0.068 \\
(0.028)\end{array}$ & $\begin{array}{c}0.002 \\
(0.019)\end{array}$ & $\begin{array}{c}0.005 \\
(0.012)\end{array}$ & $\begin{array}{c}0.019 \\
(0.011)\end{array}$ & $\begin{array}{c}0.023 \\
(0.008)\end{array}$ & $\begin{array}{c}0.024 \\
(0.009)\end{array}$ \\
\hline $25-45$ yrs old & $\begin{array}{c}0.036 \\
(0.012)\end{array}$ & $\begin{array}{c}0.030 \\
(0.007)\end{array}$ & $\begin{array}{c}0.029 \\
(0.007)\end{array}$ & $\begin{array}{c}0.013 \\
(0.006)\end{array}$ & $\begin{array}{c}0.034 \\
(0.005)\end{array}$ & $\begin{array}{c}0.016 \\
(0.006)\end{array}$ \\
\hline$>45$ yrs old & $\begin{array}{c}0.016 \\
(0.006)\end{array}$ & $\begin{array}{c}0.014 \\
(0.005)\end{array}$ & $\begin{array}{c}0.018 \\
(0.005)\end{array}$ & $\begin{array}{c}0.028 \\
(0.006)\end{array}$ & $\begin{array}{c}0.012 \\
(0.006)\end{array}$ & $\begin{array}{c}0.015 \\
(0.008)\end{array}$ \\
\hline
\end{tabular}

Note. - Standard errors in parentheses. Point estimates for $\beta_{l}$ for differentiated labor types.

\footnotetext{
${ }^{35}$ Their method can be seen as a control-function approach. Consider, as an illustration, the following production function with only one type of labor input and only an intermediate input, $M_{t}$ :

$\ln Y_{t}=\beta_{0}+\beta_{l} \ln L_{t}+\beta_{m} \ln M_{t}+\epsilon_{t}+\zeta_{t}$,

where the term $\epsilon_{t}$ represents productivity shocks that are not observable by researchers, but which can be realized by the household when they are making inputtime allocation decisions. Separately, assume the demand for $M_{t}$ varies with $\epsilon_{t}$ such that $f: M_{t}=f_{t}\left(\epsilon_{t}\right)$. Under the assumption that the intermediate input is monotonic in $\epsilon_{t}$, inverting $f_{t}$ gives: $\epsilon_{t}=f_{t}^{-1}\left(M_{t}\right)$. This function allows us to identify the coefficient in the labor input. To see this, rewrite (24) as: $\ln Y_{t}=\beta_{l} \ln L_{t}+\Phi_{t}\left(M_{t}\right)+\varepsilon_{t}$, where $\Phi$ ${ }_{t}\left(M_{t}\right)=\beta_{0}+\beta_{c} \ln M_{t}+f_{t}^{-1}\left(M_{t}\right)$. We treat $\Phi_{t}$ nonparametrically as a polynomial function of $M_{t}$ and $T_{t}$. Petrin et al. (2004) present a thorough discussion regarding the estimation procedure as well as the implementation in Stata. We follow their implementation strategy.
} 
The estimates in Table A2 are consistent with a rapid decline in the labor input in agriculture. The decline in the labor input is also very similar to the one we obtained using the log-wage profiles in Table 2. The main difference is that labor quality declines more according to our direct estimates of the production function. Overall, the estimates of TFP growth based on this shadow-wage approach are about $6.7 \%$ per year, which are very similar to results from the main text.

The shadow-wage approach relies on a household production function that allows us to examine the productivity growth similar to Eq. (20). In particular, we have estimated the following regression

$\ln Y_{i t}=\alpha_{0}+\alpha_{T} \ln T_{i t}+\alpha_{L} L_{i t}+\alpha_{t} t+\varepsilon_{i t}$,

where $Y_{i t}$ is the total output for household $i$ at time $t, T_{i t}$ is the amount of land used, $L_{i t}$ is the total working hours of a household, and $t$ indicates time. The sample size is 11,961 and the $\mathrm{R}^{2}$ of the regression is 0.27 . Our results show $\alpha_{L}=0.23$ (s.e. 0.0078 ); $\alpha_{T}=0.34$ (s.e. 0.010 ); and $\alpha_{t}=0.065$ (s.e. 0.0018 ). We use these values in the text to validate our estimates of factor shares and agricultural TFP.

Table A2

Average annual growth rate of Chinese agricultural labor input and labor quality.

\begin{tabular}{lllllll}
\hline & $1993-$ & $1997-$ & $2000-$ & $2004-$ & $2004-$ & $1993-$ \\
& 1997 & 2000 & 2004 & 2006 & 2006 & 2009 \\
\hline Labor input & -5.94 & -4.27 & -4.76 & -7.87 & -7.01 & -5.13 \\
Labor quality & -1.75 & -3.45 & -1.73 & -1.50 & -0.51 & -1.60 \\
\hline
\end{tabular}

Note. - Estimates based on a Divisia index of labor input.

\section{References}

Acemoglu, Daron, Guerrieri, Veronica, 2008. Capital deepening and nonbalanced economic growth. Journal of Political Economy 116 (3), 467-498.

Bai, Chong-En, Hsieh, Chang-Tai, Qian, Yingyi, 2006. The return to capital in China. Brookings Papers on Economic Activity, Economic Studies Program 37 (2),61-102.

Barro, Robert, Sala-i-Martin, Xavier, 1995. Economic Growth. McGraw-Hill, New York

Brandt, Loren, Rawski, Thomas, 2008. China's Great Economic Transformation. Cambridge University Press.

Brandt, Loren, Zhu, Xiaodong, 2010. Accounting for China's growth. IZA Discussion Paper 4764 .

Brandt, Loren, Hsieh, Chang-Tai, Zhu, Xiaodong, 2008. Growth and structural transformation in China. In: Brandt, Loren, Rawski, Thomas (Eds.), China's Great Economic Transformation. Cambridge University Press, pp. 569-632.

Brandt, Loren, Van Biesebroeck, Johannes, Zhang, Yifan, 2012. Creative accounting or creative destruction? Firm-level productivity growth in Chinese manufacturing. Journal of Development Economics 97 (2) 339-351.

Byrd, William, Gelb, Alan, 1991. Township, village, and private industry in China's economic reform. In: de Melo, Sapir (Ed.), Trade Theory and Economic Reform: North, South, and East: Essays in Honor of Bela Balassa. Blackwell, Oxford and Cambridge, Mass, pp. 327-349.

Caselli, Francesco, Coleman, John, 2001. The U.S. structural transformation and regiona convergence: a reinterpretation. Journal of Political Economy 109 (3), 584-616.

Chan, Kam Wing, 2012. Crossing the 50 percent population Rubicon: can China urbanize to prosperity? Eurasian Geography and Economics 53 (1), 63-86.

Chan, Kam Wing, 2013. China, internal migration. In: Ness, Immanuel, Bellwood, Peter (Eds.), The Encyclopedia of Global Migration. Blackwell Publishing.

Chang, Chun, Wang, Yijiang, 1994. The nature of the township-village enterprise Journal of Comparative Economics 19 (3), 434-452.

Chow, Gregory, 1993. Capital formation and economic growth in China. Quarterly Journal of Economics 108 (3), 809-842.

Chow, Gregory, 2007. China's Economic Transformation. Blackwell Publishing, Ltd. Oxford.

Dekle, Robert Vandenbroucke, Guillaume, 2010. Whither Chinese growth? A sectora growth accounting approach. Review of Development Economics 14 (3), 487-498.

Dekle, Robert, Vandenbroucke, Guillaume, 2012. A quantitative analysis of China's structural transformation. Journal of Economic Dynamics and Control 36 (1) 119-135.

Echevarria, Cristina, 1997. Changes in sectoral composition associated with economic growth. International Economic Review 38 (2), 431-452.

Fan, Shenggen, 1997. Production and productivity growth in Chinese agriculture: new measurement and evidence. Food Policy 22 (3), 213-228.
Fan, C. Cindy, 2008. China on the Move: Migration, the State, and the Household. Routledge, New York, NY.

Fan, Shenggen, Pardey, Philip G., 1997. Research productivity and output growth in Chinese agriculture. Journal of Development Economics 53 (1), 115-137.

Fan, Shenggen, Zhang, Xiaobo, 2002. Production and productivity growth in Chinese agriculture: new national and regional measures. Economic Development and Cultural Change 50 (4), 819-838.

Fan, Shenggen, Zhang, Xiaobo, Robinson, Sherman, 2003. Structural change and economic growth in China. Review of Development Economics 7 (3), 360-377.

Fleisher, Belton, Li, Haizheng, Zhao, Minqiang, 2010. Human capital, economic growth, and regional inequality in China. Journal of Development Economics 92 (2), 215-231.

Gollin, Douglas, Parente, Steve, Rogerson, Richard, 2002. The role of agriculture in development. American Economic Review: Papers and Proceedings 92 (2), 160-164.

Hayami, Yujiro, Ruttan, Vernon W., Southworth, Herman M., 1979. Agricultural Growth in Japan, Taiwan, Korea, and the Philippines. The University Press of Hawaii, Honolulu.

Hayashi, Fumio, Prescott, Edward, 2008. The depressing effect of agricultural institutions on the prewar Japanese economy. Journal of Political Economy 116 (4), 573-632.

Holz, Carsten A., 2009. No razor's edge: reexamining Alwyn Young's evidence for increasing interprovincial trade barriers in China. The Review of Economics and Statistics 91 (3), 599-616.

Hsieh, Chang-Tai, Klenow, Peter, 2009. Misallocation and manufacturing TFP in China and India. Quarterly Journal of Economics 124 (4), 1403-1448.

Huang, Jikun, Rozelle, Scott, 1996. Technological change: the re-discovery of the engine of productivity growth in China's rural economy. Journal of Development Economics 49 (2), 337-369.

Hulten, Charles R., 1973. Divisia index numbers. Econometrica 41 (6), 1017-1025.

Irz, Xavier, Roe, Terry, 2005. Seeds of growth? Agricultural productivity and the transitional dynamics of the Ramsey model. European Review of Agricultural Economics 32 (2), 143-165.

Jacoby, Hanan G., 1993. Shadow wages and peasant family labour supply: an econometric application to the Peruvian sierra. Review of Economic Studies 60 (4), 903-921.

Jin, Songqing, Huang, Jikun, Ruifa, Hu., Rozelle, Scott, 2002. The creation and spread of technology and total factor productivity in China's agriculture. American Journal of Agricultural Economics 84 (4), 916-930.

Johnson, D. Gale, 2000. Agriculture adjustment in China: problems and prospects. Population and Development Review 26 (2), 319-334.

Johnson, Emily, Chow, Gregory, 1997. Rates of return to schooling in China. Pacific Economic Review 2 (2), 101-113.

Jorgenson, Dale W., Gollop, Frank M., Fraumeni, Barbara M., 1987. Productivity and U.S. Economic Growth. Harvard University Press, Cambridge.

King, Robert G., Rebelo, Sergio T., 1993. Transitional dynamics and economic growth in the neoclassical model. American Economic Review 83 (4), 908-931.

Kongsamut, Piyabha, Rebelo, Sergio, Xie, Danyang, 2001. Beyond balanced growth. Review of Economic Studies 68 (4), 869-882.

Laitner, John, 2000. Structural change and economic growth. Review of Economic Studies 67 (3), 545-561.

Lardy, Nicholas, 1983. Agriculture in China's Modern Economic Development. Cambridge University Press, New York

Levinsohn, James, Petrin, Amil, 2003. Estimating production functions using inputs to control for unobservables. Review of Economic Studies 70 (2) 317-342.

Li, Haizheng, Fraumeni, Barbara M., Liu, Zhiqiang, Wang, Xiaojun, 2009. Human Capital in China. NBER Working Paper 15500.

Lin, Justin Yifu, 1992. Rural reform and agricultural growth in China. American Economic Review 82 (1), 34-51.

Lin, Justin Yifu, 1998. How did China feed itself in the past? How will china feed itself in the future? Second Distinguished Economist Lecture presented, Centro Internacional de Mejoramiento de Maiz y Trigo, Mexico, D.F., Mexico, 9 January 1998.

Lin, Justin, Yu, Miaojie, 2009. The economics of price scissors: an empirical investigation for China. Jingji Yanjiu (Economic Research) 44 (1), 42-56.

Lin, Justin Yifu, Cai, Fang, Li, Zhou, 1996. The China Miracle: Development Strategy and Economic Reform. Chinese University Press, Hong Kong.

Liu, Zhiqiang, 2005. Institution and Inequality: The Hukou System in China. Journal of Comparative Economics 33 (1), 133-157.

Matsuyama, Kiminori, 1992. Agricultural productivity, comparative advantage, and economic growth. Journal of Economic Theory 58 (2), 317-334

McMillan, John, Whalley, John, Zhu, Lijing, 1989. The impact of China's economic reforms on agricultural productivity growth. Journal of Political Economy 97 (4), 781-807.

Ngai, L. Rachel, Pissarides, Christopher A., 2007. Structural change in a multisector model of growth. American Economic Review 97 (1), 429-443.

Nin-Pratt, Alejandro, Bingxin, Yu., Fan, Shenggen, 2010. Comparisons of agricultural productivity growth in China and India. Journal of Productivity Analysis 33 (3), 209-223.

OECD, 2000. National Accounts for China: Sources and Methods. Organisation for Economic Co-operation and Development.

Olley, Steven, Pakes, Ariel, 1996. The dynamics of productivity in the telecommunications equipment industry. Econometrica 64 (6), 1263-1297.

Parente, Stephen, Prescott, Edward, 2000. Barriers to Riches. MIT Press, Cambridge.

Petrin, Amil, Poi, Brain, Levinsohn, James, 2004. Production function estimation in Stata using inputs to control for unobservables. The Stata Journal 4 (2), 113-123.

Sah, R. Kumar, Stiglitz, Joseph, 1984. The economics of price scissors. American Economic Review 74 (1), 125-138. 
Skoufias, Emmanuel, 1994. Using shadow wages to estimate labor supply of agricultural households. American Journal of Agricultural Economics 76 (2), 215-227.

Song, Zheng, Storesletten, Kjetil, Zilibotti, Fabrizio, 2011. Growing like China. American Economic Review 101 (1), 201-241.

Whalley, John, Zhao, Xiliang, 2010. The contribution of human capital to China's economic growth. NBER Working Paper 16592.

Wooldridge, Jeffrey, 2002. Econometric Analysis of Cross Section and Panel Data. MIT Press: Massachusetts Institute of Technology.

Wu, Xiang, 2003. Why did China's reforms start in the countryside? In: Howe, C., Kueh, Y.Y., Ash, R. (Eds.), China's Economic Reform: A Study with Documents. Routledge Curzon, pp. 232-241.

Wu, Shunxiang, Walker, David, Devadoss, Stephen, Yao-chi, Lu., 2001. Productivity growth and its components in Chinese agriculture after reforms. Review of Development Economics 5 (3), 375-391.
$\mathrm{Xu}$, Chenggang, 2011. The fundamental institutions of China's reforms and development. Journal of Economic Literature 49 (4), 1076-1151.

Yang, Dennis Tao, Zhu, Xiaodong, 2013. Modernization of agriculture and long term growth. Journal of Monetary Economics 60 (3), 367-382.

Yearbook, Various years. Zhongguo Tongji Nianjian [China Statistical Yearbook]. Beijing: China Statistics Press.

Young, Alwyn, 1995. The tyranny of numbers: confronting the statistical realities of the East Asian growth experience. Quarterly Journal of Economics 110 (3), 641-680.

Young, Alwyn, 2000. The razor's edge: distortions and incremental reform in the People's Republic of China. Quarterly Journal of Economics 115 (4), 1091-1135.

Young, Alwyn, 2003. Gold into base metals: productivity growth in the People's Republic of China during the reform period. Journal of Political Economy 111 (1), 1220-1261. 
Erratum

\section{Erratum to "Agricultural Productivity, Structural Change, and Economic Growth in Post-Reform China" [J. Dev. Econ., Volume 104, September 2013, pp. 165-180]}

\section{Kang Hua Cao a , Javier A. Birchenall ${ }^{\mathrm{b}, *}$}

a U.S. Department of Transportation, United States

${ }^{\mathrm{b}}$ University of California at Santa Barbara, United States

It was discovered that Fig. 1 of the above article was not correct. The correct Fig. 1 is shown below, with its correct figure legend. Fig. 1: Agricultural log-wage by age group with and without state controlled prices.

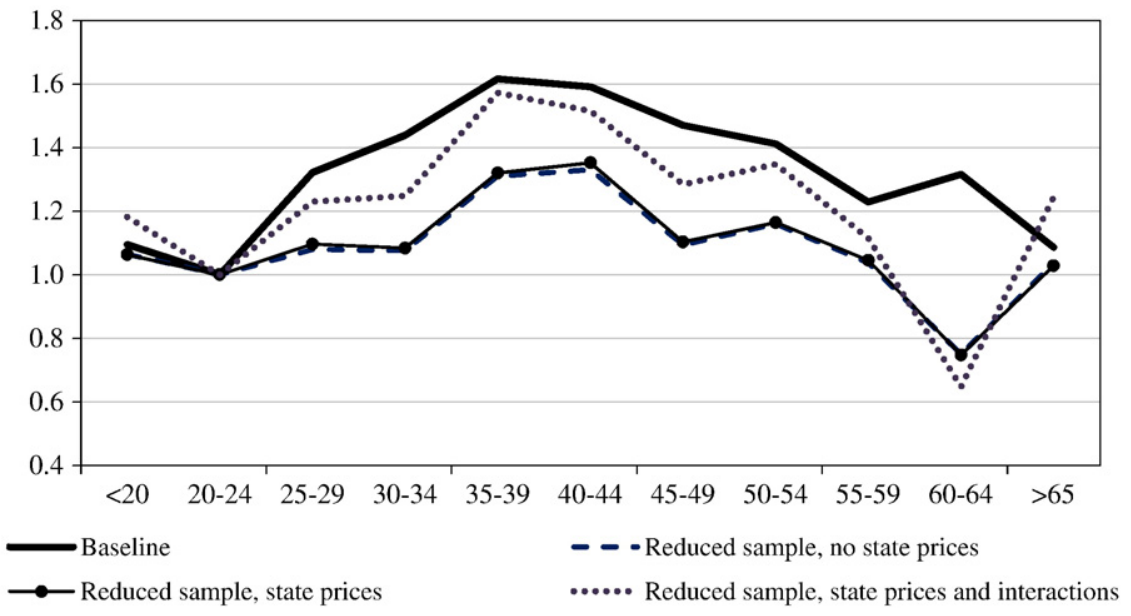

Elsevier regrets and apologizes for any inconvenience this has caused.

DOI of original article: http://dx.doi.org/10.1016/j.jdeveco.2013.06.001

* Corresponding author at: Department of Economics, 2127 North Hall, University of California, Santa Barbara, CA 93106, United States. Tel.: + 18058935275.

E-mail address: jabirche@econ.ucsb.edu (J.A. Birchenall). 